NBER WORKING PAPER SERIES

\title{
CLIMATE SHOCKS, CYCLONES, AND ECONOMIC GROWTH: BRIDGING THE MICRO-MACRO GAP
}

Laura Bakkensen

Lint Barrage

Working Paper 24893

http://www.nber.org/papers/w24893

\author{
NATIONAL BUREAU OF ECONOMIC RESEARCH \\ 1050 Massachusetts Avenue \\ Cambridge, MA 02138 \\ August 2018
}

We thank Kerry Emanuel and Wind Risk Tech, LLC for the simulated cyclone track data utilized in this analysis. We thank Tatyana Deryugina, John Hassler, and Rodolfo Manuelli for insightful discussions of this paper, and we thank Steve Cicala, Stephane Hallegatte, Sol Hsiang, William Nordhaus, Aleh Tsyvinski, Mattew Turner, Kieran Walsh, David Weil, and seminar participants at U.C. Berkeley, Yale FES, NBER EEE Summer Institute, IMF Workshop on Macroeconomic Policy and Inequality, Colby College, University of Rhode Island, SURED 2018, SED 2018 , the Federal Reserve Board, and the University of Chicago (Harris School) for their helpful feedback and comments. This work was funded exclusively through general research support funds provided to the authors by Brown University and the University of Arizona. The views expressed herein are those of the authors and do not necessarily reflect the views of the National Bureau of Economic Research.

NBER working papers are circulated for discussion and comment purposes. They have not been peer-reviewed or been subject to the review by the NBER Board of Directors that accompanies official NBER publications.

(C) 2018 by Laura Bakkensen and Lint Barrage. All rights reserved. Short sections of text, not to exceed two paragraphs, may be quoted without explicit permission provided that full credit, including $(\odot$ notice, is given to the source. 
Climate Shocks, Cyclones, and Economic Growth: Bridging the Micro-Macro Gap

Laura Bakkensen and Lint Barrage

NBER Working Paper No. 24893

August 2018

JEL No. O44,O47,Q54

\begin{abstract}
$\underline{\text { ABSTRACT }}$
Empirical analyses of climatic event impacts on growth, while critical for policy, have been slow to be incorporated into macroeconomic climate-economy models. This paper proposes a joint empirical-structural approach to bridge this gap for tropical cyclones. First, we review competing empirical approaches in a harmonized global dataset and through a theory lens. Second, we estimate cyclone impacts on structural determinants of growth (productivity, depreciation, fatalities) to quantify a stochastic growth model for 40 vulnerable countries and project welfare effects of climate-driven cyclone risk changes. Third, we compute cyclone impacts on the social cost of carbon in the seminal DICE model.
\end{abstract}

\author{
Laura Bakkensen \\ University of Arizona \\ School of Government \& Public Policy \\ 315 Social Science \\ P.O. Box 210027 \\ Tucson, AZ 85721-0027 \\ laurabakkensen@email.arizona.edu \\ Lint Barrage \\ Department of Economics \\ University of California, Santa Barbara \\ North Hall \\ Santa Barbara, CA 93106-9210 \\ and NBER \\ lint_barrage@ucsb.edu
}

An online appendix is available at http://www.nber.org/data-appendix/w24893 


\section{Introduction}

What are the macroeconomic consequences of climate change? Over the past decade, a rapidly growing body of empirical work has documented large potential growth impacts of weather shocks. While many of these studies seek to enhance our understanding of the social costs of climate change, their findings have often been slow to be incorporated into macroeconomic climate-economy models, as has been the case for other impact areas (Greenstone, 2016; Auffhammer, 2018). One general issue is that new empirical studies are often based on weather variation, whereas climate-economy models feature damages as a function of the climate, i.e., the long-run average of weather. Frontier work continues to develop econometric techniques to harness the identifying power of weather variation whilst accounting for adaptation to long-run climate change in areas such as energy demand, mortality, and agriculture (see, e.g., Deryugina and Hsiang, 2017; Auffhammer, 2018; Lemoine, 2019). However, for macroeconomic or general equilibrium impacts, there are fundamental additional challenges that must be overcome in maping reduced-form evidence into structural models. Given that policymakers use climate-economy models to quantify the social cost of carbon emissions (Greenstone, Kopits, and Wolverton, 2013), and given that growth impacts may add significantly to these costs (e.g., Moore and Diaz, 2015), this "micro-macro" gap also represents a critical policy concern (Obama, 2017).

This paper analyzes the causes of this gap and proposes a novel joint empirical-structural approach to overcome it in the context of tropical cyclones (i.e., hurricanes, typhoons). Cyclones are the leading cause of natural disaster damages world-wide $\oint^{1}$ and losses are projected to increase with global changes (e.g,. Nordhaus, 2010b; Mendelsohn et al., 2012; Ranson et al., 2014), making them a climate risk of special academic and policy interest. However, empirical estimates of cyclone impacts on economic growth have again been slow to be incorporated into climate-economy models. ${ }^{2}$ One of the first challenges facing interested modelers is that the empirical literature has found a wide range of results, ranging from positive impacts of cyclones on growth (e.g., Skidmore and Toya, 2002, "ST") to mixed impacts (e.g., Noy, 2009) and very large negative effects (e.g., Hsiang and Jina, 2014, "HJ").

First, we thus present an empirical and conceptual review of competing approaches to quantifying cyclone impacts on growth. We assemble a modern global dataset encompassing the full history of cyclones around the globe from 1970-2015 in order to revisit some of these

$1 \quad$ Comparing overall natural event losses worldwide (1998-2008) from cyclones to earthquakes/tsunamis, convective storms, winter storms, floods, and heatwaves/fires in MunichRe's NatCatService database.

2 Narita, Tol, and Anthoff (2009) use the FUND climate-economy model to project direct cyclone damage impacts on the SCC, but not growth impacts. Fried (2019) develops a general equilibrium model of weather disasters and the U.S. economy using an original quantification. We discuss these studies below. 
prior results in a harmonized sample. For example, re-estimating both a cross-sectional specification à la ST and a standard panel specification in the spirit of HJ, we find that the qualitative difference in results remains. We then argue that this difference can be resolved through the lens of macroeconomic theory. Cross-sectional regressions capture the effect of cyclone risk on average growth, which is theoretically ambiguous in several types of growth models through, e.g., precautionary savings effects. Panel fixed-effects models, on the other hand, isolate the effects of cyclone strikes, which should decrease contemporaneous growth through the destruction of productive assets. Importantly, theory also tells us that neither reduced-form approach may be individually sufficient to characterize the welfare effects of future changes as, for example, cyclone risk can affect economic growth and welfare in opposite ways.

Second, we propose and implement a novel approach to estimating and modeling cyclone impacts designed to combine empirical evidence with the structure of a model to deliver welfare cost estimates and policy implications. On the empirical side, we first quantify cyclone impacts on the structural determinants of growth, rather than on growth itself, which is typically endogenous in macroeconomic climate-economy models. Specifically, we estimate cyclone strike impacts on total factor productivity (TFP), capital depreciation, and fatalities within our global panel. On the modeling side, we present a stochastic endogenous growth cyclone-climate-economy model designed to incorporate both these estimated damage functions and the broader empirical evidence on cyclones and growth. Structurally, the model builds closely on Krebs (2003ab, 2006; see also Krebs et al., 2015) who studies the implications of business cycle and idiosyncratic human capital risks for household investment, growth, and welfare. One key feature of the model in our setting is that it makes an explicit distinction between climate and weather: households face repeated risks to their physical and human capital from cyclone strikes (weather), whose probability distribution is determined by the climate. This setup enables us to directly calibrate cyclone impacts to the plausibly causally identified estimates from panel (weather) regressions. In addition, the model structure enables us to account for some long-run general equilibrium responses to climate change that panel regressions may not be able to capture, as households respond to changing cyclone risks (climate) by adapting their savings and asset allocation decisions.

We then quantify our cyclone-climate-economy model separately for each of 40 cyclonevulnerable nations using a combination of data, estimation, matching of moments, and external calibration. The calibration includes country-specific probability density estimates of current and future cyclone risks which we compute based on 68,000 synthetic storm track simulations from Emanuel et al. (2008) and grounded in historical best track cyclone data. Comparing steady-state outcomes under the current and future climate, we find significant 
heterogeneity of projected effects, ranging from substantial negative impacts in vulnerable small island states (e.g., a -5\% welfare change in St. Vincent and the Grenadines), to small welfare gains in countries where cyclone risks are predicted to decline with global warming (e.g., Australia). The United States stands out among the most negatively impacted countries, which are otherwise mostly poor and small island states. This result is informed by prior empirical work identifying the United States as an outlier in cyclone vulnerability conditional on its income levels and exposure (e.g., Bakkensen and Mendelsohn, 2016), and highlights the importance of work investigating the determinants of adaptation to storms in the United States (e.g., Fried, 2019).

Third, in order to assess the global climate policy implications of changing cyclone risks and to illustrate the broader applicability of our approach, we integrate our cyclone impact estimates into the seminal DICE climate-economy model (Nordhaus, e.g., 1992, 2010a). As damages in DICE are a function of the global climate, we compute expected global aggregate impacts to TFP, capital depreciation, and human capital losses resulting from cyclone risk changes, and add dedicated damage functions for each component into DICE. The results suggest only a modest increase in the optimal global carbon price. That is, while some countries may suffer enormous losses from future cyclone risk increases, others are projected to experience risk declines, so that the aggregate addition to global climate damages appears modest in our setting. Of course, as further climatological projections and empirical estimates become available, it will be a rich area for future work to expand upon these quantifications and conclusions.

These findings have important research and policy implications. First, our results recontextualize empirical and theoretical understandings of the reduced-form literature on cyclones and growth. That qualitatively different results from prior studies survive in a consistent sample suggests that data improvements such as satellite-based storm measures are not sufficient to account for the difference in results. ${ }^{3}$ Instead, from a theoretical perspective, we argue that different empirical specifications capture different elements of the overall impact of cyclones on growth. By themselves, output growth regressions appear insufficient to characterize the welfare consequences of cyclone risk changes and to quantify standard macroeconomic climate-economy models, although they can provide critical insights to guide, e.g., model structure.

These findings also relate to an important parallel literature on temperature shocks and economic growth. Several influential empirical studies have documented negative economic growth impacts due to temperature shocks (e.g., Bansal and Ochoa, 2011; Dell, Jones, and

3 We do also highlight some differences in results that arise due to data variation across studies, such as sample restrictions based on macroeconomic control variable availability. 
Olken, 2012, "DJO"; Burke, Hsiang, and Miguel, 2015; Colacito, Hoffman, Phan, 2018, etc.). There have been efforts to incorporate these findings into climate-economic models. One pioneering analysis by Moore and Diaz (2015) incorporates DJO's estimates into DICE, demonstrating the potential of growth impacts to significantly increase optimal climate policy stringency. As output growth impact estimates do not provide a clear mapping into models such as DICE, Moore and Diaz (2015) consider multiple pathways, calibrating either TFP growth or capital depreciation to match DJO estimates.4 A similar issue arises in Fankhauser and Tol (2005) and Dietz and Stern (2015), who extend DICE to an endogenous longrun growth framework with capital- or investment-based knowledge spillovers, inter alia. Absent empirical guidance, they also consider a capital depreciation specification and a TFP depreciation specification. Notably, the optimal carbon price in 2015 is $55 \%$ higher with the TFP specification, again highlighting the importance of impact channels. In order to overcome these ambiguities, we propose a joint empirical-structural approach that first estimates cyclone impacts on the determinants of growth relevant for each model (e.g,. TFP, capital depreciation, fatalities) $:^{5}{ }^{6}$

Second, our approach thus highlights opportunities to reduce the "micro-macro" gap between growing empirical evidence on macroeconomic impacts and the quantification climateeconomy models. On the one hand, we show that only minor extensions of existing empirical approaches yield structurally interpretable impact estimates, such as using growth decompositions to distinguish TFP from output growth effects. On the other hand, we also demonstrate how modifying structural models to make weather explicit permits (i) direct incorporation of plausibly causally identified impact estimates, (ii) accounting for macroeconomic adaptation through endogenous adjustments in savings and investments, and (iii) computing welfare costs of changes in climatic risks. These three goals match the desirable properties of climate impact quantification identified by Auffhammer (2018) and Greenstone (2016).

$4 \quad$ More and Diaz (2015) ultimately focus on the TFP pathway. Supplementary results for the depreciation pathway suggest broadly similar patterns but a significantly higher social cost of carbon. Gauging visually from the relevant graphs, the SCC appears to reach well over $\$ 1,500+$ per ton by 2080 for depreciation damages, compared to around $\$ 1,000$ per ton for the TFP pathway in the benchmark.

5 Alternative approaches include, e.g., Bansal and Ochoa (2011) who present a Long-Run Risk model calibrated to their own estimates of temperature shock growth impacts. Consumption growth is a given process in this model; that is, it is not a production-based growth model, thus side-stepping questions of impact mechanisms.

6 A growing number of studies present climate-economy models with growth impacts but without focus on empirical connections. Bretschger and Valente (2011) provide a theoretical foundation for climate change growth impacts through multiple channels (capital and TFP depreciation). Lemoine (2019) presents an endowment economy-based IAM with temperature impacts on consumption growth to study the implications of uncertainty for the SCC. Of course there is also a large general theoretical literature on the environment and endogenous growth (e.g,. Bovenberg and Smulders, 1995). 
On the quantitative modeling side, our analysis complements several advancements in the literature. Perhaps most closely related in methodology, Fried (2019) presents a dynamic general equilibrium model of the U.S. economy where heterogeneous households face risks of capital destruction from storms. She presents an original calibration using, e.g., U.S. Federal Emergency Management Agency (FEMA) disaster assistance across regions, and utilizes the model to quantify adaptation capital, FEMA policy effects, and the role of adaptation in mitigating welfare costs from future storm intensity increases. Hallegatte et al. (2007) develop a 'non-equilibrium dynamic model' (NEDyM) of disasters and apply it to extreme weather events (albeit not cyclones) $]^{7}$ in Europe. NEDyM builds on a Solow growth model with limits on reconstruction investment and non-clearing short-run labor and goods markets. As both our model structure and research goals are fundamentally different, we abstract from some of the important nuances featured in these studies, and focus instead on detailed linkages to empirical reduced-form approaches and long-run growth impacts under aggregate risk. 8 The broader literature also features seminal contributions on rare disasters in macroeconomics and finance (e.g., Barro, 2006; Pindyck and Wang, 2013), but cyclones are typically not examples of such rare disasters. ${ }^{9}$

Lastly, we contribute new estimates of the impact of a major climate risk - tropical cyclones - on the social cost of carbon. Previously, Narita, Tol, and Anthoff (2009) used the FUND model to estimate climate change impacts on direct cyclone damages, fatalities, and the SCC. Our analysis advances their approach in several ways including by (i) adding TFP damages, (ii) estimating country-specific damage functions over wind speeds, (iii) estimating country-specific cyclone probability distributions based on new climatological research (Emmanuel et al., 2008) and (iv) formally computing expected damages. Despite these new features, we ultimately find a similar result, namely that cyclones add only modestly to the optimal global carbon price. This aggregate result masks considerable global heterogeneity, however, and for many countries - including the United States - cyclone risk changes are likely to be a first-order climate concern.

$7 \quad$ Hallegatte (2009) combines empirical direct cyclone impact estimates for the United States with estimates of the relationship between direct and indirect losses (based on a case study applying an InputOutput model to Hurricane Katrina's sectoral impacts) to project total economic losses from hurricanes in the United States both with and without climate change-induced hurricane intensity increases.

8 For example, besides structural differences, Fried (2019) features no aggregate risk from storms which are assumed to be evenly distributed across space in the United States. In contrast, we study aggregate growth impacts of cyclone risk across 40 vulnerable countries. Similarly, Hallegatte et al. (2007) focus on short-run transitional additions to overall disaster costs. While we also depart from the standard Ramsey model to capture the persistence of disaster losses, our model allows for long-run growth effects through changes in asset allocations and savings rates (exogenous in NEDyM).

9 Cyclones are common in many countries and physically limited (Emanuel and Holland, 2011). Pindyck and Wang (2013) define catastrophic shocks as reducing capital by "more than 10 or 15 percent." In our data, even the 95 th percentile of capital destruction is only 2.8 percent. 


\section{Revisiting Empirical Approaches}

\subsection{Data}

The first step in our analysis is to compile a harmonized global panel of cyclones and relevant economic indicators at the country-year level.

Cyclone Data: Building on best practices in the literature (Hsiang and Jina, 2014), we gather historical global tropical cyclone tracks from the International Best Track Archive for Climate Stewardship (IBTrACS; Knapp et al., 2010). Considered the most comprehensive record of global historical tropical cyclone tracks by the World Meteorological Organization, IBTrACS contains best track records of cyclone position and intensity characteristics collected from meteorological agencies across the world. We focus on 1970-2015, the postsatellite era for which cyclones have been most reliably tracked. For all 3,346 cyclone landfalls during this period, we calculate cyclone intensity metrics including annual maximum wind speed at landfall (in knots) and annual energy (the sum of cubes of wind speeds recorded within a country), a metric based on the power dissipation index developed by Emanuel (2008) ${ }^{10}$ We process the tracks in ArcGIS and aggregate data up to the country-year level 11 Next, in order to estimate future changes in cyclone risks, we incorporate 68,000 simulated future tropical cyclone tracks based on advancements in climatological research by Kerry Emanuel and co-authors (Emanuel, 2008; Emanuel, Sundararajan, and Williams, 2008). These synthetic tracks and their usage are described in detail in Section 4 .

Macroeconomic Indicators: We collect annual national-level macroeconomic indicators including real GDP (2011 \$US), physical and human capital stocks, and population from the Penn World Tables 9.0 ("PWT", Feenstra et al., 2015). We also collect educational attainment estimates from Barro and Lee (2012). Though not directly used in our analysis, we further obtain World Bank data (from World Development Indicators) on several other macroeconomic indicators (gross capital formation and imports, foreign direct investment, and government surplus all as percentage of GDP) included in analyses such as Noy (2009) in order to construct a comparable sample based on data availability (described in Section 2.1 .2 .

Geography: Country areas and absolute latitudes are collected from the Harvard WorldMap.

$\overline{10}$ Given that some cyclone wind speeds are listed as zero while a cyclone necessarily has non-zero wind speeds, we interpolate missing wind speeds from minimum pressure readings following Atkinson and Holliday (1977). For a minority of observations missing both wind and pressure, we assume a wind speed of 35 knots for categorized cyclones and 25 knots for tropical depressions. Lastly, we convert 1 minute sustained wind speeds to 10 minute sustained wind speeds for unit consistency.

11 We process the data without a dedicated wind-field model. For recent advancements on such modeling, see, e.g., Strobl (2011), Hsiang and Narita (2012), Hsiang and Jina (2014). 
We calculate the fraction of a country's population residing within 100 kilometers of navigable water (defined as a coast, major river, or major lake) in ArcGIS using geospatial shoreline data from NOAA's Global Self-consistent, Hierarchical, High-resolution Geography Database and population data from the Gridded Population of the World v4 produced by the Center for International Earth Science Information Network (CIESIN) at Columbia University and as published through NASA's Socioeconomic Data and Applications Center (SEDAC). We calculate in ArcGIS the fraction of a country's land area in a tropical climate zone based on Köppen-Geiger climate classification maps provided by Rubel and Kottek (2010). Finally, we collect information on countries' populations living below five meters of elevation from the Low Elevation Coastal Zone Urban-Rural Population and Land Area Estimates, from CIESIN and SEDAC.

Institutions: We consider several measures of institutions across countries, including the "Statistical Capacity Rating" from the World Bank and the "Corruptions Perception Index" from Transparency International. In line with the broader disasters literature (e.g., Noy, 2009; McDermott et al., 2014), we consider the World Bank's measure of domestic credit provided by the financial sector (as a percentage of GDP) as a proxy for financial market development. Finally, we obtain estimates of natural disaster insurance rates from MunichRe's NatCatService, a leading industry data source on disaster losses. We specifically collect data on insured versus total economic losses from meteorological events from 19982018 by country income group, and compute the average insured fractions.

Cyclone Damages: Finally, we obtain cyclone damage estimates from two sources. Our benchmark measure of property damages and fatalities is gathered from EMDAT, the International Disaster Database (Guha-Sapir et al., 2016). EMDAT is the most comprehensive publicly available database on disaster losses and arguably the most widely used in the literature (e.g., Skidmore and Toya, 2002; Raddatz, 2007; Noy, 2009; Hsiang and Narita, 2012 ; etc.). At the same time, EMDAT data are subject to certain data quality caveats (e.g., Hsiang and Narita, 2012). While comparative analyses with proprietary damage data from global re-insurance companies fail to indicate that these would necessarily dominate EMDAT data coverage (Guha-Sapir et al., 2002), for robustness, we also consider damage estimates from MunichRe. We specifically use country-year aggregates of total direct losses from cyclones as computed by Neumayer, Plumper, and Barthel (2014) from the MunichRe database.

\subsubsection{Cross-Sectional Estimates}

Conceptually, a natural starting point for exploring the association between the climate and economic outcomes has been through cross-sectional analyses. As famously noted by Mendel- 
sohn, Nordhaus, and Shaw (1994) in an early empirical study of agriculture and climate, a cross-sectional approach enables researchers to study the independent variable of interest - the long-run climate - and thus impacts net of all relevant adaptation margins. A core concern with this approach is omitted variable bias, on account of which many scholars have considered panel and mixed approaches instead (Auffhammer, 2018). Here, we nonetheless begin with a discussion of the cross-sectional approach. We argue that, in the context of natural disasters and economic growth, cross-sectional analyses provide both unique insights and entail conceptual limitations above and beyond standard econometric concerns which are important to consider. For example, even a perfectly identified cross-sectional regression would provide only limited insights into welfare and Integrated Assessment Model (IAM) quantification, but can inform the structure of IAMs seeking to capture cyclone growth impacts.

In the empirical literature, Skidmore and Toya (2002, "ST") present an early and highly influential analysis which regresses countries' average 1960-90 growth rates on disaster metrics such as the average number of climatic events per year in country $j$ in a sample of 89 countries. They document a positive correlation between disasters and growth. This result differs markedly from subsequent literature which typically finds negative impacts in panel analyses, as discussed in Section 2.1.2. Hsiang and Jina (2015) moreover document a negative cross-sectional relationship between average cyclone-induced capital depreciation and growth. From an empirical perspective, one may first raise questions about Skidmore and Toya's results vis-à-vis the literature based on the data differences. For example, ST (2002) use countries' reported disaster occurrences in EMDAT to measure general disaster risk, which are subject to several inclusion criteria and thus constitute a partly selected sample. More recent work has thus moved towards using meteorological data to measure climatic events (e.g., Hsiang and Jina, 2014). More broadly, modern data also span a longer time period $(+25$ years since 1990) and larger sets of countries.

To begin our empirical examination, we first revisit a cross-sectional specification building on Skidmore and Toya (2002) in our harmonized global dataset. Specifically, we regress each country $j^{\prime} s$ average growth rate from 1970-2015 $\left(\bar{g}_{j}\right)$ on different cyclone risk measures $\left(\mu_{\varepsilon, j}\right)$ and a host of control variables $\left(\mathbf{X}_{\mathbf{j}}\right)$, including the fraction of land area in the tropics, absolute latitude, our water access measure, an institutional quality proxy, and initial GDP per capita. 12

$$
\bar{g}_{j}=\beta_{0}+\beta_{1} \mu_{\varepsilon, j}+\mathbf{X}_{\mathbf{j}}^{\prime} \boldsymbol{\beta}+\epsilon_{j}
$$

12 A central challenge in correlating cyclone risk with economic growth is that the climate is not randomly distributed across space, and likely correlated with other factors that may influence growth, such as geography (Hall and Jones, 1996) and institutions (Acemoglu, Johnson, Robinson, 2001). We thus include these controls for geography and institutional quality in the cross-sectional specification. 
Table 1 presents the results. Column (1) confirms that a significant positive correlation between economic growth and ST's main disaster risk measure, the natural logarithm of disaster counts (per land area), survives in our extended global sample using modern meteorological data. Before describing the rest of the results, we discuss their theoretical foundations.

Conceptually, cross-sectional regressions capture the impact of average storm risk on average growth. Broadly speaking, a vast literature in macroeconomics analyzes the effects of different kinds of (uninsurable) risks on economic growth and welfare (e.g., Bewley, 1977; Lucas, 1987; Ayiagari, 1994; Krebs, 2003ab, etc.). In recent years, a number of theoretical analyses have focused on natural disaster risks and growth in particular, including several studies that allow disaster probabilities or damages to depend on pollution stocks. Examples of the latter include Ikefuji and Horii (2012), Müller-Fürstenberger and Schumacher (2015), and Bretschger and Vinogradova (2016); Akao and Sakamoto (2013) characterize the effects of exogenous disaster risk on growth. The theoretical insights we invoke here are based both on this literature and can also be shown to hold within our own model (see Section 5 and Online Appendix).

From a macro-theoretical perspective, one may expect the relationship between cyclone risk and long-run growth to be ambiguous in sign as economic risks can affect growth through numerous channels. Though the details depend on the growth model in question, some general mechanisms can be noted. First, an increase in economic risk may generally induce households to save more, that is, to undertake precautionary savings (e.g., Bewley, 1977). Ceteris paribus, an increase in savings rates can increase average growth rates across a range of models, including (i) in a Solow growth model during the transition to a long-run balanced growth path, (ii) in an endogenous growth model with aggregate capital externalities (see, e.g., Devereux and Smith, 1993), (iii) in an AK-type endogenous growth model (see, e.g., Krebs, 2006), and (iv) in a Lucas (1988)-style model of human capital-driven growth (see, e.g., Ikefuji and Horii, 2012). Second, an increase in storm risks can alter growth by changing households' optimal portfolio choice. That is, to the extent that cyclone risk alters the relative attractiveness of different investment options (e.g., human versus physical capital), an increase in cyclone risk may also alter overall returns by changing the composition of an economy's investments. Ceteris paribus, such a portfolio effect could lower average growth through a 'flight to safety' of lower return assets, or could increase average growth by increasing human capital in models where it is a driver of growth (as in, e.g., Akao and Sakamoto, 2013). A third impact channel is that higher storm risk may have a direct negative effect on growth (ceteris paribus) by increasing average depreciation rates, in line with Hisang and Jina's (2015) empirical findings, and also by lowering average productivity. Importantly, from a theoretical perspective, the overall impact of cyclone risk on long-run 
growth is thus ambiguous in sign. In the context of our model (presented in Section 2), we further demonstrate how this relationship may specifically be non-monotonic even within a given economy (see Online Appendix).

In light of these considerations, we next extend the standard cross-sectional specification (1) à la ST to allow for quadratic effects of cyclone risk on growth. The results in Table 1 Columns (2) and (4) confirm significant non-monotonicity: cyclone risk is positively correlated with economic growth initially, but this association turns negative at higher levels of risk. As a final empirical check on the relevance of the aforementioned theoretical mechanisms, we add controls for average savings rates and educational attainment to (11). The results in Columns (3) and (5) reveal that the initial positive association between cyclone risk and growth is attenuated in both magnitude and precision once these controls are added, consistent with the theoretical prediction that higher savings and human capital investment rates are a part of the underlying mechanism. 
Table 1: Cross-Sectional Cyclone Risk and Growth Association

\begin{tabular}{|c|c|c|c|c|c|}
\hline \multirow{2}{*}{$\begin{array}{l}\text { Dependent Variable: } \\
\text { Cyclones }_{j} \\
\text { Measure: }\end{array}$} & \multicolumn{5}{|c|}{ Avg. Real GDP/Capita Growth $\bar{g}_{1970-2015, j}$} \\
\hline & $\ln \left(\frac{\text { Landfalls }}{\text { sqkm }}\right)$ & \multicolumn{2}{|c|}{ Landfalls/sqkm } & \multicolumn{2}{|c|}{ Max. Wind/sqkm } \\
\hline & $(1)$ & $(2)$ & $(3)$ & $(4)$ & $(5)$ \\
\hline$\overline{\text { Cyclones }_{j}}$ & $\begin{array}{c}0.100^{* * *} \\
(0.032)\end{array}$ & $\begin{array}{c}185.934^{* *} \\
(76.478)\end{array}$ & $\begin{array}{l}135.233 \\
(93.210)\end{array}$ & $\begin{array}{l}7.077^{* *} \\
(3.516)\end{array}$ & $\begin{array}{c}5.765 \\
(3.565)\end{array}$ \\
\hline$\left(\overline{\text { Cyclones }_{j}}\right)^{2}$ & & $\begin{array}{c}-6,470.275^{* *} \\
(2,695.255)\end{array}$ & $\begin{array}{l}-6,647.325^{*} \\
(3,999.375)\end{array}$ & $\begin{array}{c}-11.266^{* *} \\
(5.562)\end{array}$ & $\begin{array}{c}-11.733^{*} \\
(6.281)\end{array}$ \\
\hline$\overline{\text { SavingsRate }_{j}}$ & & & $\begin{array}{c}0.093^{* * *} \\
(0.022)\end{array}$ & & $\begin{array}{c}0.092^{* * *} \\
(0.022)\end{array}$ \\
\hline$\overline{\text { YearsSchooling }_{j}}$ & & & $\begin{array}{c}0.009 \\
(0.064)\end{array}$ & & $\begin{array}{c}0.020 \\
(0.063)\end{array}$ \\
\hline Tropics (\%Area) & $\begin{array}{c}-0.009^{*} \\
(0.005)\end{array}$ & $\begin{array}{c}-0.011^{* *} \\
(0.005)\end{array}$ & $\begin{array}{l}-0.008 \\
(0.005)\end{array}$ & $\begin{array}{c}-0.010^{* *} \\
(0.005)\end{array}$ & $\begin{array}{l}-0.007 \\
(0.005)\end{array}$ \\
\hline Abs. Latitude & $\begin{array}{l}-0.015 \\
(0.013)\end{array}$ & $\begin{array}{l}-0.021 \\
(0.014)\end{array}$ & $\begin{array}{l}-0.017 \\
(0.014)\end{array}$ & $\begin{array}{l}-0.021 \\
(0.014)\end{array}$ & $\begin{array}{l}-0.016 \\
(0.014)\end{array}$ \\
\hline Water Proximity (\%Area) & $\begin{array}{c}0.001 \\
(0.005)\end{array}$ & $\begin{array}{c}0.004 \\
(0.005)\end{array}$ & $\begin{array}{c}0.012^{* * *} \\
(0.005)\end{array}$ & $\begin{array}{c}0.004 \\
(0.005)\end{array}$ & $\begin{array}{c}0.013^{* * *} \\
(0.005)\end{array}$ \\
\hline Institutions $\left(\mathrm{CPI}_{2015}\right)$ & $\begin{array}{c}0.030^{* * *} \\
(0.009)\end{array}$ & $\begin{array}{c}0.035^{* * *} \\
(0.009)\end{array}$ & $\begin{array}{l}0.016^{*} \\
(0.009)\end{array}$ & $\begin{array}{c}0.035^{* * *} \\
(0.009)\end{array}$ & $\begin{array}{c}0.015 \\
(0.009)\end{array}$ \\
\hline Initial GDP/Cap. 1970 & $\begin{array}{c}-0.000^{* * *} \\
(0.000)\end{array}$ & $\begin{array}{c}-0.000^{* * *} \\
(0.000)\end{array}$ & $\begin{array}{c}-0.000^{* * *} \\
(0.000)\end{array}$ & $\begin{array}{c}-0.000^{* * *} \\
(0.000)\end{array}$ & $\begin{array}{c}-0.000^{* * *} \\
(0.000)\end{array}$ \\
\hline Observations & 131 & 132 & 113 & 132 & 113 \\
\hline Adj. R-Squared & 0.303 & 0.274 & 0.392 & 0.261 & 0.398 \\
\hline $\begin{array}{l}\text { Table presents OLS regression } \\
\text { log of avg. number of cyclone la } \\
\text { of landfalls per year normalized } \\
\text { wind speed per year normalized } \\
\text { for the share of land area in the } \\
\text { lake, or coast, the Transparency } \\
\text { a constant. Cols. (3) and (5) fu } \\
\text { errors are heteroskedasticity-rob }\end{array}$ & $\begin{array}{l}\text { f countries' avg. } \\
\text { ndfalls per year } \\
\text { by area in levels } \\
\text { by area in levels } \\
\text { tropics, absolute } \\
\text { International Co } \\
\text { ther control for } \\
\text { ust and presente }\end{array}$ & $\begin{array}{l}\text { eal GDP per cap } \\
0.0000001 \text { norma } \\
\text { Cols. 2, 3) and } \\
\text { Cols. 4, 5) and } \\
\text { value of latitude, } \\
\text { ruption Percepti } \\
\text { vg. savings rates } \\
\text { in parentheses ( }\end{array}$ & $\begin{array}{l}\text { ta growth rate } \\
\text { ized by area (C } \\
\text { uared (Col. 3), } \\
\text { uared (Col. 5). } \\
\text { fraction of pop. } \\
\text { ns Index, initia } \\
\text { and avg. years } \\
* * \mathrm{p}<0.01, * *\end{array}$ & $\begin{array}{l}1970-2015) \text { on } \\
\text { l. } 1 \text { ), the avg } \\
\text { or avg. max. } \\
\text { All specificat } \\
\text { within } 100 \mathrm{~km} \\
\text { (1970) GDP } \\
\text { f schooling. S } \\
<0.05, * \text { p }<\end{array}$ & $\begin{array}{l}\text { natural } \\
\text { number } \\
\text { istained } \\
\text { ns control } \\
\text { f major river } \\
\text { r capita, and } \\
\text { ndard } \\
\text { 1). }\end{array}$ \\
\hline
\end{tabular}

Lessons and Limitations: Climate change is altering the distribution of cyclone risks across the globe (e.g., Emanuel, 2008; see also Section 4). In principle, the coefficients of a cross-sectional specification such as (1) thus represent the relevant thought experiment for predicting the corresponding long-run growth impacts of climate change. The results are consistent with the theoretical predictions that growth impacts may be empirically relevant and occurring through countervailing channels such as precautionary savings and direct losses. While the cross-sectional results are thus qualitatively informative, there are at least two core limitations on their quantitative use in inferring climate change costs. The first is the potential for omitted variable bias inherent in cross-country comparisons. The second 
and more fundamental concern is that growth impacts need not be informative about welfare. It is long known that changes in economic risk can affect growth and welfare in opposite ways (see, e.g., Devereux and Smith, 1993). For example, if higher cyclone risk increases growth by increasing precautionary savings, this change is clearly welfare-reducing. The Online Appendix formally confirms the possibility of higher growth but lower welfare in the context of our model. Consequently, even a perfectly identified cross-sectional growth regression would not be sufficient to quantify welfare impacts of cyclone risk changes. In sum, these results thus highlight the need for a structural approach to capture both the welfare and general equilibrium effects of climate-induced changes in future cyclone risks.

\subsubsection{Panel Estimates}

The most common empirical approach to studying natural disaster impacts on growth is to use panel variation. This literature has documented a range of results, with most finding broadly negative effects of varying magnitude and duration (reviewed by, e.g., Kousky, 2014) but some finding no impacts in all but the most extreme disasters (Cavallo et al., 2013). Prior research has already identified several study design features which can contribute to differences in results. For example, Loayza et al. (2009) document heterogeneous impacts across disaster types (e.g., earthquakes versus storms). Similarly, different proxies for disaster intensity (e.g., property damages versus fatalities) have been shown to yield different results (e.g., Noy, 2009).

Thus, we next consider a panel specification in our harmonized global sample. That is, we focus on one disaster type (cyclones), meteorological intensity measures (e.g., maximum wind speeds), and a standard panel fixed-effects specification similar to Hsiang and Jina (2014):

$$
g_{j, t}=\gamma_{j}+\delta_{t}+\left(\theta_{j} \cdot t\right)+\sum_{l=0}^{L} \beta_{1+l} \varepsilon_{j, t-l}+\beta_{I n t}\left(q_{j, t} \cdot \varepsilon_{j, t}\right)+\epsilon_{j, t}
$$

Here, $g_{j, t}$ is a country's annual real GDP per capita growth rate, $\gamma_{j}$ are country fixed-effects, $\left(\theta_{j} \cdot t\right)$ are country-specific linear time trends, and $\varepsilon_{j, t-l}$ are cyclone realization measures (e.g., maximum wind speed) up to lag $L$. Here we focus on contemporaneous impacts $(L=0)$, but consider richer lag structures in our main empirical impact channel estimation in Section 3. The empirical literature has frequently found that disaster impacts vary with country characteristics, particularly the level of development and the quality of (financial) institutions (e.g., Kahn, 2005; Loayza et al., 2009; Noy, 2009; Raddatz 2009; Fomby, Ikeda, and Loayza, 2013; McDermott et al., 2014). Specification (2) consequently allows for the impact of 
cyclones to vary with covariates $q_{j, t}$, specifically domestic credit or lagged GDP per capita. ${ }^{13}$ Standard errors $\epsilon_{j, t}$ are heteroskedasticity-robust and clustered at the country level.

In reviewing the empirical literature, we document another potential source of variation in results: sample composition based on macroeconomic control variable availability. That is, prior studies differ in the supplemental controls they include in panel growth regressions alongside disaster measures. One classic example, Noy (2009), includes a rich set of controls such as government budget surplus and foreign exchange reserves, permitting a final sample of 109 countries. Numerous other recent studies end up with similar or smaller samples, ${ }^{14}$ whereas, e.g., Cavallo et al. (2013) use a synthetic controls approach and construct certain variables permitting a sample of 196 countries. In order to gauage whether such sample differences may be contributing to differences in studies' results, we estimate (2) for two samples: (i) "Unfiltered" includes all available countries (182 countries), whereas (ii) "Has Controls" includes only country-years for which control variables such as used by Noy (2009) and others are available in our sample ${ }^{15}$ We do not actually include those controls in the regressions so as to isolate sample effects.

Tables 2 present the results for landfall counts and maximum wind speed (normalized by land area) as intensity metrics. Results for energy are presented in the Online Appendix (Table A1). First, the results generally confirm that cyclone strikes have a negative effect on contemporaneous economic growth. That is, in the same global analysis that yields a positive cross-sectional correlation between growth and cyclone risk, we find a negative effect of cyclone strikes. Second, we note that the statistical precision of these results differs notably across the unfiltered and data-restricted country samples. In the unfiltered sample, contemporaneous cyclone impacts are precisely estimated only for energy, whereas they are generally significantly different from zero in the data-restricted sample, broadly in line with some of the underlying heterogeneity in the literature ${ }^{16}$ Table 3 compares some key

13 We lag GDP to avoid endogeneity to the year $t$ disaster realization, but consider contemporaneous credit as it reduces impacts precisely through its response to disasters.

14 For example, Loyaza et al. (2012) have a sample of 94 countries and Fomby et al. (2013) study 84 countries.

15 We specifically define a sample of country-years that have data on gross capital formation, domestic credit, imports as percentage of GDP, foreign direct investment, government surplus, and countries that have at any point had institutional quality ratings from the International Country Risk Guide (ICRG). This sample does not match Noy's exactly due to changes in source databases over time. We also do not purchase the ICRG data and utilize public metadata instead (URL: https://epub.prsgroup.com/available-countries). If countries have entered this database since the time of Noy's (2009) analysis, they may also change the relative samples. Importantly, our goal is not to replicate Noy's sample per se, but to demonstrate how a representative example of standard controls can affect the sample precision and results.

16 For example, studies such as Noy (2009) have found significant negative effects of disasters on growth, whereas Cavallo et al. (2013) do not except in the largest disasters. Of course, there are many other methodological differences across these and other studies, and it is beyond the scope of our study to 
attributes of the two samples. We find that countries in the typical data-restricted sample feature significantly higher average Statistical Capacity Ratings, significantly lower volatility in GDP growth, and significantly larger average populations than the unfiltered sample, likely contributing to the difference in precision of the estimated results. Finally, in line with prior studies, we see that these negative growth impacts are generally lower in countries with better financial institutions (proxied by domestic credit, Columns (2) and (5)) and higher levels of development (Columns (3) and (6)).

formally decompose differences in results across these factors. 
Table 2: Panel Analysis: Cyclone Strikes and Growth

\begin{tabular}{|c|c|c|c|c|c|c|}
\hline \multirow[t]{3}{*}{ Dependent Variable: } & \multicolumn{6}{|c|}{ Real GDP/Capita Growth ${ }_{j, t}$} \\
\hline & \multicolumn{3}{|c|}{ Unfiltered } & \multicolumn{3}{|c|}{ Has Controls } \\
\hline & $(1)$ & $(2)$ & $(3)$ & (4) & $(5)$ & $(6)$ \\
\hline$\#$ Landfalls/sqkm $j, t$ & $\begin{array}{c}0.637 \\
(1.282)\end{array}$ & $\begin{array}{c}-1.970 \\
(20.518)\end{array}$ & $\begin{array}{l}-19.395 \\
(33.566)\end{array}$ & $\begin{array}{c}-67.112^{* *} \\
(29.058)\end{array}$ & $\begin{array}{c}-472.355^{* *} \\
(191.126)\end{array}$ & $\begin{array}{c}-1,212.980^{* * *} \\
\quad(427.418)\end{array}$ \\
\hline $\operatorname{Credit}_{j, t} \cdot\left(\#\right.$ Landfalls $\left./ \mathrm{sqkm}_{j, t}\right)$ & & $\begin{array}{c}0.010 \\
(0.273)\end{array}$ & & & $\begin{array}{c}5.370^{* *} \\
(2.669)\end{array}$ & \\
\hline $\ln (\text { GDP p.c. })_{j, t-1} \cdot\left(\#\right.$ Landfalls $/$ sqkm $\left._{j, t}\right)$ & & & $\begin{array}{c}1.962 \\
(3.308)\end{array}$ & & & $\begin{array}{c}115.904^{* * *} \\
(41.925)\end{array}$ \\
\hline Domestic Credit $_{j, t}$ & & $\begin{array}{l}-0.000 \\
(0.000)\end{array}$ & & & $\begin{array}{c}-0.000^{* *} \\
(0.000)\end{array}$ & \\
\hline $\ln (\text { GDP p.c. })_{j, t-1}$ & & & $\begin{array}{c}-0.103^{* * *} \\
(0.013)\end{array}$ & & & $\begin{array}{c}-0.220^{* * *} \\
(0.033)\end{array}$ \\
\hline Adj. R-Squared & 0.110 & 0.0985 & 0.165 & 0.177 & 0.201 & 0.277 \\
\hline Max. Wind/sqkm $j, t$ & $\begin{array}{c}0.004 \\
(0.050)\end{array}$ & $\begin{array}{l}-0.899 \\
(1.202)\end{array}$ & $\begin{array}{l}-2.708 \\
(2.065)\end{array}$ & $\begin{array}{c}-2.280^{* * *} \\
(0.298)\end{array}$ & $\begin{array}{c}-3.731^{* *} \\
(1.821)\end{array}$ & $\begin{array}{l}-5.183 \\
(9.959)\end{array}$ \\
\hline 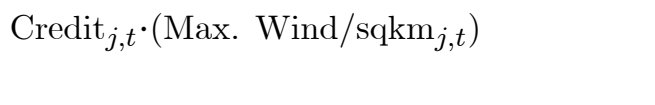 & & $\begin{array}{c}0.010 \\
(0.015)\end{array}$ & & & $\begin{array}{c}0.020 \\
(0.023)\end{array}$ & \\
\hline $\ln (\text { GDP p.c. })_{j, t-1} \cdot\left(\right.$ Max. Wind $\left./ \mathrm{sqkm}_{j, t}\right)$ & & & $\begin{array}{c}0.275 \\
(0.207)\end{array}$ & & & $\begin{array}{c}0.306 \\
(0.993)\end{array}$ \\
\hline Domestic Credit $_{j, t}$ & & $\begin{array}{l}-0.000 \\
(0.000)\end{array}$ & & & $\begin{array}{c}-0.000^{* *} \\
(0.000)\end{array}$ & \\
\hline $\ln (\text { GDP p.c. })_{j, t-1}$ & & & $\begin{array}{c}-0.103^{* * *} \\
(0.013)\end{array}$ & & & $\begin{array}{c}-0.219^{* * *} \\
(0.033)\end{array}$ \\
\hline Adj. R-Squared & 0.110 & 0.0993 & 0.166 & 0.178 & 0.200 & 0.278 \\
\hline Observations & 7,573 & 5,690 & 7,573 & 1,978 & 1,978 & 1,978 \\
\hline \#Countries & 182 & 171 & 182 & 116 & 116 & 116 \\
\hline Country F.E.s: & Yes & Yes & Yes & Yes & Yes & Yes \\
\hline Year F.E.s: & Yes & Yes & Yes & Yes & Yes & Yes \\
\hline Country-Trends: & Yes & Yes & Yes & Yes & Yes & Yes \\
\hline S.E. Cluster & Country & Country & Country & Country & Country & Country \\
\hline $\begin{array}{l}\text { Table presents regression of countries' real GDP } \mathrm{p} \\
\text { panel) or max. wind speed per sqkm. in year } t \mathrm{pl} \\
\text { with storms (Cols.3,6) or domestic credit provide } \\
\text { regressions include country fixed effects, year fixed } \\
\text { are heteroskedasticity-robust and clustered at the }\end{array}$ & $\begin{array}{l}\text { capita grov } \\
\text { controls fo } \\
\text { by financial } \\
\text { effects, coun } \\
\text { ountry level. }\end{array}$ & $\begin{array}{l}\text { th rate in ye } \\
\text { lagged natu } \\
\text { sector }(\% \mathrm{GD} \\
\text { ry-specific li } \\
(* * * \mathrm{p}<0.0\end{array}$ & $\begin{array}{l}\text { ar } t \text { on numbe } \\
\text { ral log of real } \\
\text { P) in level anc } \\
\text { eear time trenc } \\
1, * * \text { p }<0.05 \text {, }\end{array}$ & $\begin{array}{l}\text { a of cyclone } l \\
\text { GDP per capi } \\
\text { interacted w } \\
\text { ls and a cons } \\
\text { p }<0.1)\end{array}$ & $\begin{array}{l}\text { dffalls per sqk } \\
\text { in level and i } \\
\text { hstorms (Cols } \\
\text { ant. Standard }\end{array}$ & $\begin{array}{l}\text { (top } \\
\text { teracted } \\
2,5) \text {. All } \\
\text { rrors }\end{array}$ \\
\hline
\end{tabular}




\begin{tabular}{|c|c|c|c|c|}
\hline \multicolumn{5}{|c|}{ Table 3: Sample Comparison } \\
\hline & & \multicolumn{2}{|c|}{ Sample } & \multirow[b]{2}{*}{ Diff. (SE) } \\
\hline & & "Unfiltered" & "Has Controls" & \\
\hline Population & Mean & 31.1 & 49.1 & $\begin{array}{l}-18.0 \\
(3.40)^{* * *}\end{array}$ \\
\hline Statistical Capacity Rating & Mean & 68.2 & 74.2 & $\begin{array}{l}-6.0 \\
(0.70)^{* * *}\end{array}$ \\
\hline \multirow[t]{2}{*}{ Real GDP p.c. Growth } & & & & $\begin{array}{l}-0.4 \% \\
(0.12)^{* *} \\
\end{array}$ \\
\hline & Var. & $6.7 \%$ & $4.2 \%$ & $\mathrm{f}=2.53^{* * *}$ \\
\hline \multicolumn{5}{|c|}{$\begin{array}{l}\text { Table compares means or variance for indicated variables across "Unfiltered" and "Has Controls" } \\
\text { samples of country-years. Means are compared with two-sided t-tests (with Welch approximation } \\
\left.\text { for unequal variances). Variance compared with F-test. ( }{ }^{* * *} \mathrm{p}<0.01,{ }^{* *} \mathrm{p}<0.05,{ }^{*} \mathrm{p}<0.1\right) \text {. }\end{array}$} \\
\hline
\end{tabular}

Lessons and Limitations: On the one hand, panel specifications such as (2) are clearly attractive in terms of econometric identification. Cyclone impacts $\beta_{1}$ are identified based on variation in cyclone realizations across years within each country, and thus plausibly causal. On the other hand, given the findings and theoretical considerations described in Section 2.1.1. we would expect the fixed effects related to countries' average growth rates in (2), $\gamma_{j}$ and $\theta_{j}$, to remain endogenous to cyclone risk. This endogeneity becomes important if one wishes to use panel estimates to predict the growth impacts of climate change. That is, while some empirical studies have analyzed climate change impacts by evaluating (2) at alternative potential future storm realizations $\widetilde{\varepsilon}_{j, \tau}$ (e.g., Hsiang and Jina, 2014), our analysis suggests that this approach is incomplete as climate change will also alter baseline cyclone risks and thus average growth rates as in Table 1. In a prior version of this paper (Bakkensen and Barrage, 2016), we explored a two-step estimator to evaluate cyclone impacts through both channels; however, this analysis remains subject to the core concern that growth impacts do not correspond to welfare effects.

Despite these limitations, panel output growth regressions can provide essential insights to inform the design of environment-economy models. For example, limited financial markets are clearly an empirically relevant contributor to vulnerability, but not accounted for in many IAMs. Another common empirical finding is that negative cyclone strike impacts on output levels appear persistent (e.g., Raddatz, 2007; Strobl, 2011; Hsiang and Jina, 2014; Elliott et al., 2015). This stylized fact is at odds with a standard Ramsey model, which would imply a growth rebound after the initial negative impact, motivating the exploration of alternative frameworks. 


\section{Modified Empirical Approach}

\subsection{Total Factor Productivity}

Though the empirical literature frequently focuses on GDP per capita growth as an outcome variable, these impact estimates are difficult to incorporate directly into macroeconomic climate-economy models as GDP growth is typically endogenized. In contrast, climate impacts upon structural model parameters are straightforward to interpret and utilize. We thus begin by conducting a standard growth accounting exercise that decomposes cyclone output growth impacts into productivity versus factor input changes. The appropriate empirical specification depends on the structure of the climate-economy model for which the estimates are intended. First, in the seminal DICE framework, countries produce GDP $Y_{j, t}$ with capital $K_{j, t}$ and labor $L_{j, t}^{P o p}$ (measured by population) inputs via Cobb-Douglas technology:

$$
Y_{j, t}=A_{j, t}^{D I C E} K_{j, t}^{\alpha_{D}}\left(L_{j, t}^{P o p}\right)^{1-\alpha_{D}}
$$

Taking logs and rearranging yields:

$$
\ln \left(A_{j t}^{D I C E}\right)=\ln \left(Y_{j, t}\right)-\alpha_{D} \ln \left(K_{j, t}\right)-\left(1-\alpha_{D}\right)\left[\ln \left(L_{j, t}^{P o p}\right)\right]
$$

Using Penn World Tables (PWT) data on GDP, capital stocks, and populations, one can thus back out 'DICE TFP' from (4) given the relevant capital share $\left(\alpha_{D I C E}=0.67\right)$.

For DICE, climate change impacts on human capital factors such as educational attainment should thus be counted in TFP. In contrast, other models may endogenize human capital accumulation. Indeed, in light of the potential links between cyclone risks and human capital (e.g., Skidmore and Toya, 2002; Ikefuji and Horii, 2012), our model specifies production as a Cobb-Douglas aggregate of physical and human capital stocks:

$$
Y_{j, t}=A_{j, t} K_{j, t}^{\alpha_{j, t}} H_{j, t}^{1-\alpha_{j, t}}
$$

For this specification, the appropriate TFP series is given by:

$$
\ln \left(A_{j, t}\right)=\ln \left(Y_{j, t}\right)-\alpha_{j, t} \ln \left(K_{j, t}\right)-\left(1-\alpha_{j, t}\right)\left[\ln \left(h c_{j, t}\right)+\ln \left(L_{j, t}^{P o p}\right)\right]
$$

We map (6) into the data following standard approaches (e.g., Hall and Jones, 1999) that specify human capital-augmented labor $H_{j, t}$ as the product of the number of workers $L_{j, t}$ and human capital per worker $h c_{j, t}$. The latter, in turn, is provided by PWT based on schooling data and returns to education estimates (Inklaar and Timmer, 2013). As our model features 
inelastic labor supply, we also use $L_{j, t}^{P o p}$ as a measure of workers. Following Gollin (2002) we assume common labor shares across countries and set $1-\alpha_{j t}=0.67 \forall j, t$.

The preferred specification de-trends each TFP series log-linearly through the inclusion of country-specific time trends $\left(\gamma_{j} \cdot t\right)$ and year fixed-effects $\delta_{t}$ in an estimating equation which follows the standard panel approach (analogous to (2) but for TFP):

$$
\ln \left(A_{j, t}\right)=\gamma_{j}+\delta_{t}+\left(\theta_{j} \cdot t\right)+\sum_{l=0}^{L} \beta_{1+l}^{A} \varepsilon_{j, t-l}+\epsilon_{j, t}
$$

where $\gamma_{j}$ denotes country fixed-effects and $\varepsilon_{j, t-l}$ are cyclone realization measures up to lag $L$. Standard errors $\epsilon_{j, t}$ are heteroskedasticity-robust and clustered at the country level. We consider a range of values of $L$. Table 4 presents results for maximum wind speed per sqkm.

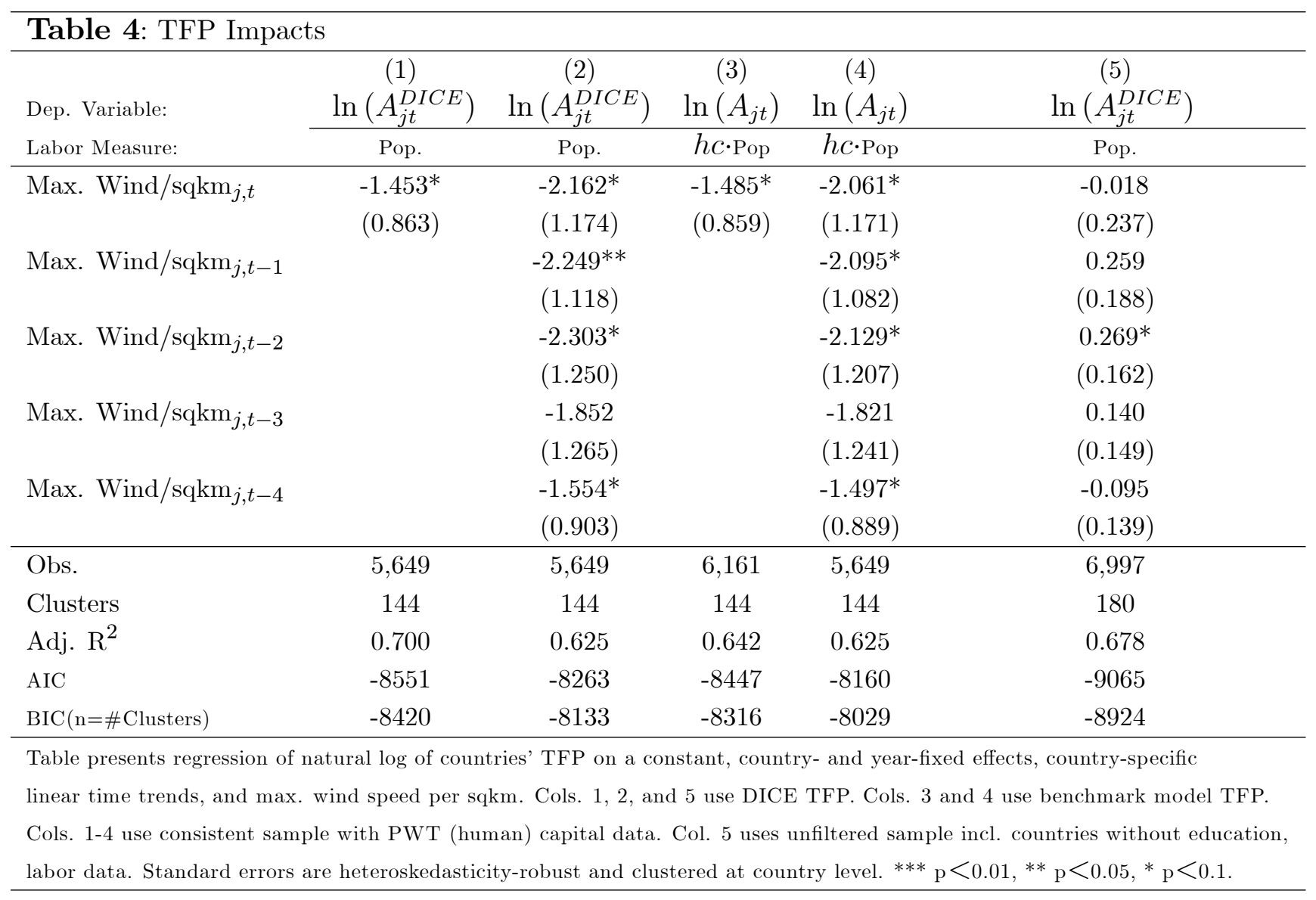

The results indicate significant negative impacts of cyclone strikes on both TFP measures. Columns (1)-(4) present estimates for a consistent sample of countries. While both the Bayesian and Akaike information criteria are minimized for the contemporaneous impacts specifications (Cols. 1 and 3), we also find negative and at least marginally precisely esti- 
mated TFP impacts persisting up to around 5 years. The Online Appendix shows results for alternative lag structures. Additional lags reduces the estimates' precision, but leave the magnitudes similar. For completeness, Column (5) presents estimates of the DICE TFP impacts on the unfiltered sample of available country-years for this indicator. That is, compared to Column (2), Column (5) add 36 countries that lack PWT data on education and/or employment, which renders the cyclone impact estimates noisy, echoing the results of Section 2.1.2. The Online Appendix shows additional results for specifications that (i) de-trend TFP through HP-filtering, which leads to broadly similar results, and (ii) use energy as cyclone intensity measure, which yields somewhat noisier estimates. Overall, the results thus suggest that one of the channels through which cyclone strikes affect realized growth is by lowering TFP17

\subsection{Depreciation}

While there is limited literature guidance for the estimation of cyclone TFP impacts, numerous studies have quantified cyclone destruction of property and human life as a function of storm characteristics. Following these studies (e.g., Kahn, 2005; Nordhaus, 2010b; Schumacher and Strobl, 2011; Hsiang and Narita, 2012), we specify polynomial damage functions:

$$
\begin{aligned}
\eta_{j, t}^{k}\left(\varepsilon_{j, t}\right) & \equiv \frac{\text { PropertyDamages }_{j, t}}{K_{j, t}}=\xi_{1 j, t}^{k}\left(\varepsilon_{j, t}\right)^{\xi_{2 j, t}^{k}} \\
\eta_{j, t}^{h}\left(\varepsilon_{j, t}\right) & \equiv \frac{\text { Fatalities }_{j, t}}{L_{j, t}}=\xi_{1 j, t}^{h}\left(\varepsilon_{j, t}\right)^{\xi_{2, j, t}^{h}}
\end{aligned}
$$

Our setup allows the damage function coefficients to vary across countries and time, in line with the results of prior literature. We specifically estimate (8) in logs: 18

$$
\ln \left(\eta_{j, t}^{m}\right)=\mathbf{x}_{j, t}^{\prime} \boldsymbol{\beta}^{\mathbf{m}}+\beta_{\varepsilon}^{m} \ln \varepsilon_{j, t}+\left(\ln \varepsilon_{j, t} \cdot \mathbf{x}_{\mathbf{j}, \mathbf{t}}\right)^{\prime} \boldsymbol{\gamma}^{\mathbf{m}}+\epsilon_{j, t}, m \in\{k, h\}
$$

Given (9) one can infer countries' vulnerability coefficients as a function of their covariates $\mathbf{x}_{j, t}^{\prime}$ :

$$
\begin{aligned}
& \widehat{\xi_{1, j, t}^{m}}=e^{\mathbf{x}_{j, t}^{\prime} \widehat{\boldsymbol{\beta}^{\mathbf{m}}}} \\
& \widehat{\xi_{2, j, t}^{m}}=\widehat{\beta}_{\varepsilon}+\mathbf{x}_{\mathbf{j}, \mathbf{t}}^{\prime} \gamma^{\mathbf{m}}
\end{aligned}
$$

$17 \quad$ Loayza et al. (2012) consider a productivity impact channel for disasters by including capital investment rates in several output impact regressions, but do not estimate a structural damage function for TFP impacts.

18 Since we use the same explanatory variables for physical capital and fatality regressions, a seemingly unrelated regression (SUR) approach would not change the results. 
Table 5 displays the results for our preferred cyclone measure of maximum wind speed (per square kilometer). As expected, depreciation losses are increasing in wind speeds, albeit with heterogeneous steepness across countries. Column (1) adopts country fixed effects as damage covariates $\mathbf{x}_{j, t}^{\prime}$. This specification allows countries to differ in baseline damages conditional on experiencing a cyclone, but with common curvature in wind speed. Given the empirical literature's finding that damage curves are considerably steeper in the United States (e.g., Nordhaus, 2010b; Strobl, 2011) than globally (Hsiang and Narita, 2012; Bakkensen and Mendelsohn, 2016), Column (2) presents a U.S.-only specification, which confirms this pattern ${ }^{19}$

Finally, Columns (4) and (6) allow depreciation damages to vary with countries' levels of economic development and the population share living below five meters elevation in coastal zones. Importantly, while there are many other potential determinants of countries' cyclone vulnerability, these are two covariates we would expect to have first-order relevance and for which we can obtain projections of future levels in order to consider potential changes in countries' future vulnerabilities. As expected, the results indicate that both physical and human capital depreciation impacts are significantly larger in countries with larger population shares in low-lying coastal areas, and significantly mitigated in countries with higher economic development.

19 Quantitatively, the results may differ from studies normalizing damages by GDP as we study damages as a fraction of countries' capital stocks, which are not equiproportional to GDP across countries. 
Table 5: Depreciation Impacts

\begin{tabular}{|c|c|c|c|c|c|c|}
\hline \multirow[t]{2}{*}{ Dependent Variable: } & \multicolumn{4}{|c|}{$\ln \left(\right.$ PropertyDamages $\left._{j, t} / K_{j, t}\right)$} & \multicolumn{2}{|c|}{$\ln \left(\right.$ Fatalities $\left._{j, t} / L_{j, t}\right)$} \\
\hline & (1) & $(2)$ & $(3)$ & $(4)$ & $(5)$ & $(6)$ \\
\hline \multirow{2}{*}{$\ln \left(\operatorname{MaxWind}_{j, t}\right)$} & $1.112^{* *}$ & $4.704^{* * *}$ & $2.034^{* * *}$ & $2.209^{* * *}$ & $0.771^{* * *}$ & $1.967^{* * *}$ \\
\hline & $(0.530)$ & $(0.959)$ & $(0.564)$ & $(0.559)$ & $(0.226)$ & $(0.339)$ \\
\hline \multirow{2}{*}{$\ln \left(\operatorname{MaxWind}_{j, t}\right) \cdot \ln \left(\mathrm{GDP}_{\mathrm{pc}}\right)_{j, t-1}$} & & & $-0.164^{* *}$ & $-0.201^{* * *}$ & & $-0.150 * * *$ \\
\hline & & & $(0.064)$ & $(0.064)$ & & $(0.037)$ \\
\hline \multirow[t]{2}{*}{$\ln \left(\operatorname{MaxWind}_{j, t}\right) \cdot(\text { Pct. Below } 5 \mathrm{~m})_{j, t}$} & & & & $0.023^{* * *}$ & & $0.011^{* *}$ \\
\hline & & & & $(0.007)$ & & $(0.005)$ \\
\hline \multirow[t]{2}{*}{$\ln (\operatorname{GDP} \mathrm{pc})_{j, t-1}$} & & & $-1.940 * * *$ & $-2.352^{* * *}$ & & $-2.088 * * *$ \\
\hline & & & $(0.644)$ & $(0.645)$ & & $(0.370)$ \\
\hline \multirow[t]{2}{*}{ Pct. Below $5 \mathrm{~m}_{j, t}$} & & & & $0.198^{* * *}$ & & $0.081^{* *}$ \\
\hline & & & & $(0.062)$ & & $(0.038)$ \\
\hline \multirow[t]{2}{*}{ Constant } & 1.456 & $45.304^{* * *}$ & $13.797^{* *}$ & $16.045^{* * *}$ & $-6.891^{* * *}$ & $10.373^{* * *}$ \\
\hline & $(4.784)$ & $(10.957)$ & $(5.574)$ & $(5.520)$ & $(2.042)$ & $(3.357)$ \\
\hline Country Fixed Effects? & Yes & U.S. Only & No & No & Yes & No \\
\hline Observations & 356 & 29 & 356 & 356 & 472 & 471 \\
\hline Adj. R-Squared & 0.0350 & 0.401 & 0.218 & 0.236 & 0.0316 & 0.489 \\
\hline \multicolumn{7}{|c|}{$\begin{array}{l}\text { Table presents regression of natural } \log \text { of fractions of capital stock destroyed (Cols. 1-4) or population killed (Cols. } 5-6) \text { on } \\
\text { natural } \log \text { of MaxWind } j, t \text { (max. wind speed normalized by country area), lagged GDP per capita levels and max. wind } \\
\text { interactions (Cols. } 3,4,6 \text { ), the percentage of population living below } 5 \text { meters elevation in levels and max. wind interactions } \\
\text { (Cols. } 4,6 \text { ), and country fixed-effects (Cols. } 1,5) \text {. Col. } 2 \text { restricts sample to U.S. storms only. Damage data source is EMDAT. } \\
\text { Heteroskedasticity-robust standard errors in parentheses }\left({ }^{* * *} \mathrm{p}<0.01,{ }^{* *} \mathrm{p}<0.05,{ }^{*} \mathrm{p}<0.1 \text { ). }\right.\end{array}$} \\
\hline
\end{tabular}

Table 5 is estimated using EMDAT data on cyclone damages. For robustness, we repeat the specification using MunichRe data (see Online Appendix Table A6). On the one hand, the MunichRe data yield steeper wind speed curvature estimates in the fixed effects specifications (e.g., U.S. damage elasticity of 5.9 instead of 4.7). On the other hand, the specifications with interaction terms are comparatively attenuated. We consider these results for robustness in our structural analysis below.

\section{Cyclone Risk Changes}

The empirical estimates presented thus far quantify the impacts of weather shocks $\varepsilon_{j, t}$. Linking these estimates to climate-economy models requires a quantification of how the probability distribution of these shocks will change along with the global climate, indexed by global mean surface temperature $T_{\tau}$ in decade $\tau$, specifically cyclone probability density functions $(p d f s) f_{j}\left(\varepsilon \mid T_{\tau}\right)$. The availability of atmospheric science data to estimate such $p d f s$ was previously limited, forcing some earlier literature to evaluate damage functions at the projected future means of cyclone intensity, effectively computing damages at expected intensity rather 
than expected damages (e.g., Narita, Tol, Anthoff, 2009; see also review by Ranson et al., 2014). Of course, if damage functions $\delta^{k}\left(\varepsilon_{j, t}\right)$ are convex, this approach risks underestimating expected future impacts. In this paper we gratefully take advantage of advances in climatological research from Kerry Emanuel and co-authors (Emanuel, 2008; Emanuel, Sundararajan, and Williams, 2008; and as utilized by Mendelsohn et al., 2012) to construct estimates of cyclone $p d f$ s. Their work generates 68,000 simulated synthetic tropical cyclone tracks under each of the current (1980-2000) and future climate, specifically 2080-2100 under the IPCC's A1B emissions scenario and processed through four different general circulation models. Our benchmark analysis focuses on results using NOAA's GFDL model (17,000 simulated tracks; Manabe et al., 1991), but we also consider alternatives in our sensitivity analysis below. The synthetic cyclone tracks contain parallel information to the historical record, such as storm latitude, longitude, and wind speeds at points along the track life. Recent literature that has used synthetic tracks to inform both current cyclone risk assessments (Hallegatte, 2007; Elliott, Strobl, Sun, 2015) and projections of direct cyclone damages from climate change (Hallegatte, 2009; Mendelsohn et al., 2012).

In order to estimate cyclone pdfs at the country-year level, we conduct Monte Carlo simulations based on current and future landfall frequencies and sampling from either the historical cyclone record (to estimate current risk) or from synthetic tracks (to estimate future risk) (see Online Appendix). Importantly, this process captures changes in expected future intensity driven both by changes in the number and characteristics of storms. For landfall frequencies, we adopt a Poisson distribution (Emanuel, 2013). For our preferred cyclone measure of maximum wind speeds, the literature has found Weibull distributions to provide the best fit (Johnson and Watson 2007), which we consequently use to estimate cyclone $p d f s$ for each country. ${ }^{20}$ To validate this approach, we compare the expected annual maximum wind speeds from the Weibull model against empirically observed means in the data. The Weibull model reproduces the data extremely well, with a correlation coefficient of 0.9982 (plotted in Online Appendix Figure A1).

In order to illustrate the potential impacts of climate change on cyclone risks, Figure 1 next compares the current (from data) and projected future maximum wind speed distribution for four example countries. The simulations indicate highly heterogeneous impacts, with cyclone risk increases in some regions (e.g., United States), but decreases in others (e.g.,

20 While 'fat tails' have been noted as a concern for some climate risks, cyclone wind speeds face a physical upper bound (Holland and Emanuel, 2011), and fitting even a log-normal distribution can imply "meteorologically unrealistic" upper tail behavior of excessive wind speeds (Johnson and Watson, 2007). Relatedly, Conte and Kelly (2016) find that cyclone damages in the United States follow a fat tailed distribution due to the spatial distribution of properties, but that household-level damages and the wind speed distribution are thin tailed. We account for uniquely high U.S. damages by utilizing a separate capital depreciation elasticity. 
Australia). Countries are also predicted to experience heterogeneous changes in the variability of cyclone intensity, with tightening distributions in some (e.g., India), but increasing variability in others. Figure 2 presents results for a broader set of countries, specifically by comparing current annual maximum wind speeds (x-axis) against expected future annual maximum wind speeds (y-axis). By comparing the location of each point (country) against the plotted $45^{\circ}$ line, we see again some countries are predicted to experience substantial increases in average risk, whereas others are predicted to see declines in average cyclone activity.

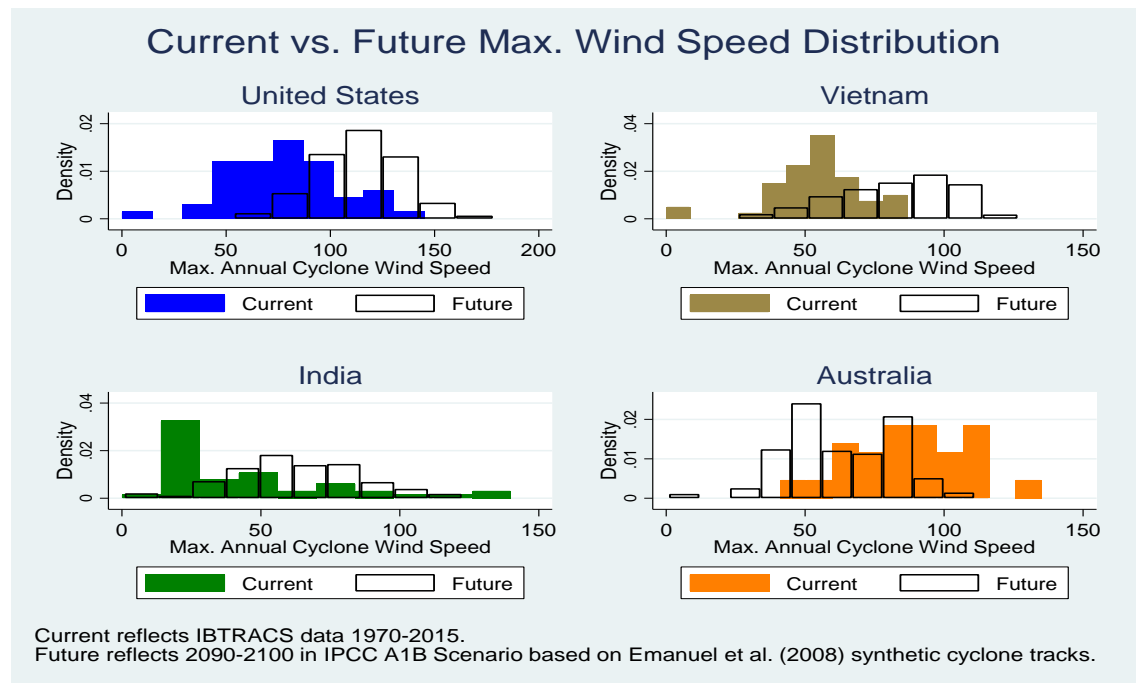

Figure 1 


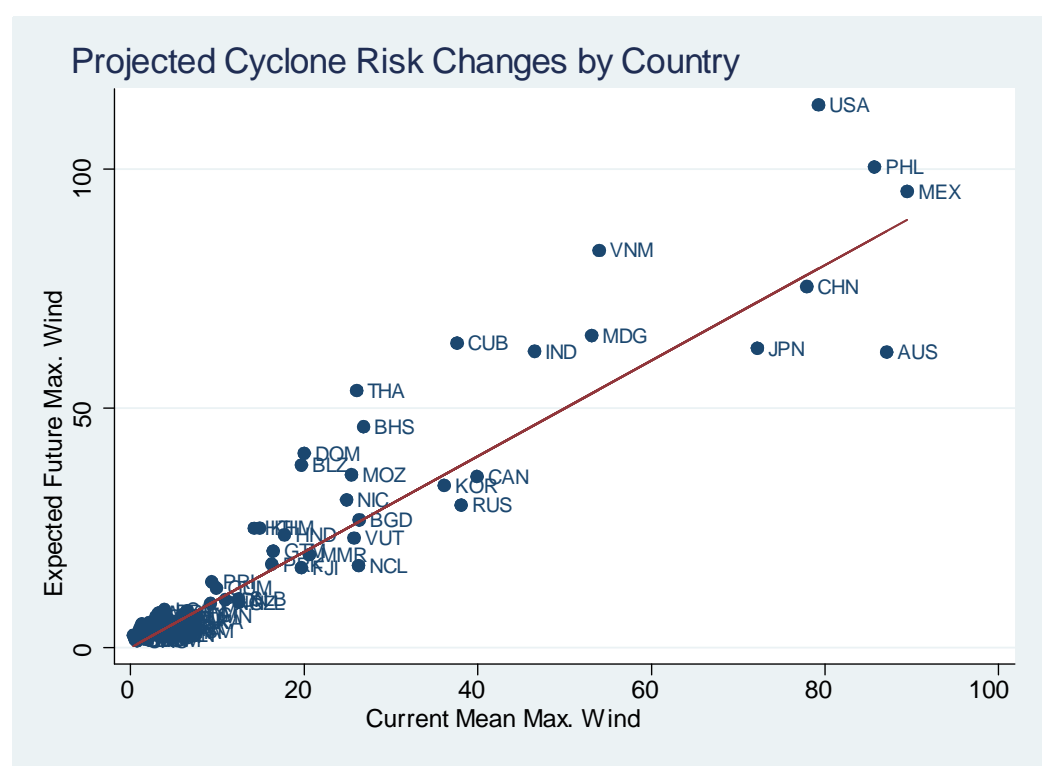

Figure 2

\section{$5 \quad$ Stochastic Endogenous Growth Cyclone-Economy Model}

This section presents our country-specific stochastic endogenous growth cyclone-economy model designed to incorporate the empirical evidence from Section 3. The framework builds closely on Krebs (2003ab, 2006; see also Krebs et al., 2015), who develops a heterogeneous agent version of this class of model to study the implications of idiosyncratic human capital and business cycle risks for household savings, investment, growth, and welfare. We consider a representative agent economy but allow for (i) correlated shocks to both human and physical capital, (ii) partial insurance availability, and (iii) an application and damage specification to natural disaster risk, specifically tropical cyclones. As the prior theory literature has analyzed disaster impacts in other endogenous growth models (e.g., Ikefuji and Hoori, 2012), our fundamental contribution here is that we bring such a model to the data. That is, we produce a novel integration of empirical evidence into a structural model, and produce quantitative estimates of growth and welfare impacts resulting from cyclone risk changes for 40 countries. In particular, we show that making the econometrically identifying level of variation (weather realizations) explicit in the structure of model allows for a straightforward integration of empirically estimated impact functions into an environment-economy model. 


\subsubsection{Model Setup}

Each country $j$ is inhabited by a representative household who can invest in human capital $\left(h_{j, t}\right)$ and physical capital $\left(k_{j, t}\right)$. Both assets are at risk for cyclone depreciation shocks $\eta_{j}^{h}\left(\varepsilon_{j, t}\right), \eta_{j}^{k}\left(\varepsilon_{j, t}\right)$ that depend on realized disaster intensity $\varepsilon_{j, t}{ }^{21}$ We represent financial market incompleteness in a reduced-form way by assuming that fraction $\pi_{j}$ of damages can be insured at actuarially fair rates, so that, with risk-averse agents, $\left(1-\pi_{j}\right)$ denotes the fraction of uninsured damages ${ }^{22}$ The representative agent in country $j$ chooses state-contingent plans for consumption $c_{j, t}$ and investments in human and physical capital $\left(x_{j, t}^{h}, x_{j, t}^{k}\right)$ to maximize:

$$
\max E_{j, 0} \sum_{t=0}^{\infty} \beta^{t} u\left(c_{j, t}\right)
$$

$$
\begin{aligned}
\text { s.t. }: & c_{j, t}+x_{j, t}^{k}+x_{j, t}^{h}=k_{j, t} R_{j, t}^{k}+h_{j, t} R_{j, t}^{h} \\
k_{j, t+1}= & \left(1-\underline{\delta_{k}}-\pi_{j} \mu_{j}^{k}-\left(1-\pi_{j}\right) \eta_{j}^{k}\left(\varepsilon_{j, t}\right)\right) k_{j, t}+x_{j, t}^{k} \\
h_{j, t+1}= & \left(1-\underline{\delta_{h}}-\pi_{j} \mu_{j}^{h}-\left(1-\pi_{j}\right) \eta_{j}^{h}\left(\varepsilon_{j, t}\right)\right) h_{j, t}+x_{j, t}^{h} \\
& k_{j, 0}, h_{j, 0} \text { given }
\end{aligned}
$$

Here, $R_{j, t}^{k}$ and $R_{j, t}^{h}$ denote returns to physical and human capital, $\underline{\delta_{m}}$ denotes baseline depreciation of asset $m$, and $\mu_{j}^{m} \equiv E_{j}\left[\eta_{j}^{m}(\varepsilon)\right]$ denotes the expected cyclone damages to asset $m$. We include insurance premia $\pi_{j} \mu_{j}^{m}$ in the capital laws of motion for ease of illustration as both assets are produced linearly from the final consumption good. Disaster intensity follows some iid distribution $\varepsilon_{j, t} \sim f_{j}\left(\varepsilon_{j} \mid T_{\tau}\right)$ in each country with mean $\mu_{j, \varepsilon} \equiv E_{j}\left[\varepsilon_{j, t}\right]$. We suppress the dependence of mean damages and mean intensity on the climate $T_{\tau}$ for notational simplicity.

Aggregate production by the representative firm rents households' factors $K_{j, t} \equiv k_{j, t} L_{j}$ and $H_{j, t} \equiv h_{j, t} L_{j}$ in competitive national markets, where $L_{j}$ denotes the country's population.

$$
\max _{K_{j, t}, H_{j, t}} A_{j, t}\left(\varepsilon_{j, t}\right) K_{j, t}^{\alpha} H_{j, t}^{1-\alpha}-R_{j, t}^{k} K_{j, t}-R_{j, t}^{h} H_{j, t}
$$

Here $A_{j, t}\left(\varepsilon_{j, t}\right) \equiv \bar{A}_{j, t}\left(1-\eta^{A}\left(\varepsilon_{j, t}\right)\right)$ denotes total factor productivity, which also depends on storm realizations. ${ }^{23}$ Next, letting $\widetilde{k}_{j, t} \equiv \frac{k_{j, t}}{h_{j, t}}$ denote the household's physical-human capital

$\overline{21}$ We now suppress the time subscripts on the damage functions $\eta_{j}^{h}(),. \eta_{j}^{k}($.$) as the model treats these as$ constant within the current steady-state. In comparing present and future steady-states, however, we later allow for the possibility that damage functions change along with cyclone risks.

23 Our benchmark quantification focuses on contemporaneous TFP impacts of $\eta^{A}\left(\varepsilon_{j, t}\right)=\widehat{\beta_{1}^{A}} \varepsilon_{j, t}$ from Col. 1 in Table 4. For robustness we also consider a cumulative 5 -year impact specification $\left(\eta^{A}\left(\varepsilon_{j, t}\right)=\right.$ 
ratio, and noting that, in equilibrium, by market clearing, $\widetilde{k}_{j, t}=\widetilde{K}_{j, t} \equiv \frac{K_{j, t}}{H_{j, t}}$, factor returns are given by:

$$
\begin{aligned}
R_{j, t}^{k} & =(\alpha) A_{j, t}\left(\varepsilon_{j, t}\right) \cdot\left(\widetilde{k}_{j, t}\right)^{\alpha-1} \\
R_{j, t}^{h} & =(1-\alpha) A_{j, t}\left(\varepsilon_{j, t}\right) \cdot\left(\widetilde{k}_{j, t}\right)^{\alpha}
\end{aligned}
$$

Let the household's wealth at time $t$ be defined by the sum of his physical and human capital: $w_{j, t} \equiv k_{j, t}+h_{j, t}$. Further let $\widetilde{s}_{j, t} \equiv 1-\frac{c_{j, t}}{w_{j, t}\left(1+r_{j}\left(\widetilde{k}_{j, t}, \varepsilon_{j, t}\right)\right)}$ denote the household's savings-outof-wealth ratio, let $\omega_{k}\left(\widetilde{k_{j, t}}\right) \equiv\left(\frac{\widetilde{k}_{j, t}}{1+\widetilde{k}_{j, t}}\right)$ be the share of the household's wealth invested in physical capital, and let $\bar{\delta}_{j}^{m} \equiv \underline{\delta}_{m}+\pi_{j} \mu_{j}^{m} m \in\{k, h\}$ denote the known proportional annual losses of asset $m$ (baseline depreciation plus insurance premia). The household's realized return on his portfolio at time $t$ is then given by the weighted sum of net returns on physical and human capital:

$$
\begin{aligned}
r_{j}\left(\widetilde{k_{j, t}}, \varepsilon_{j, t}\right) \equiv & \omega_{k}\left(\widetilde{k_{j, t}}\right)\left[R_{j, t}^{k}\left(\widetilde{k}_{j, t}, \varepsilon_{j, t}\right)-\overline{\delta_{j}^{k}}-\left(1-\pi_{j}\right) \eta_{j}^{k}\left(\varepsilon_{j, t}\right)\right] \\
& +\left(1-\omega_{k}\left(\widetilde{k_{j, t}}\right)\right)\left[R_{j, t}^{h}\left(\widetilde{k}_{j, t}, \varepsilon_{j, t}\right)-\overline{\delta_{j}^{h}}-\left(1-\pi_{j}\right) \eta_{j}^{h}\left(\varepsilon_{j, t}\right)\right]
\end{aligned}
$$

Finally, we assume that preferences are of the standard form:

$$
u\left(c_{j, t}\right)=\frac{c_{j, t}^{1-\gamma}}{1-\gamma} \text { if } \gamma \neq 1,=\log \left(c_{j, t}\right) \text { if } \gamma=1
$$

Equilibrium Growth Following Krebs (2003b), it is straightforward to show (see Online Appendix) that the capital ratio $\widetilde{k}_{j}$ and the savings rate $\widetilde{s}_{j}$ that solve the household's problem in stationary equilibrium (where $\widetilde{k}_{j, t}={\widetilde{k_{j}}}_{\text {and }} \widetilde{s}_{j, t}={\widetilde{s_{j}}}_{\text {) }}$ are jointly determined by:

$$
\begin{aligned}
\widetilde{s}_{j} & =\left(\beta E_{j}\left[\left(1+r_{j}\left(\widetilde{k}_{j}^{\prime}, \varepsilon_{j}^{\prime}\right)\right)^{1-\gamma}\right]\right)^{\frac{1}{\gamma}} \\
0 & =\beta E_{j}\left[\frac{\left.\left[R_{j}^{k}\left(\widetilde{k}_{j}, \varepsilon_{j}^{\prime}\right)-\overline{\delta_{j}^{k}}-\left(1-\pi_{j}\right) \eta_{j}^{k}\left(\varepsilon_{j}^{\prime}\right)\right]-\left[R_{j}^{h}\left(\widetilde{k}_{j}, \varepsilon_{j}^{\prime}\right)-\overline{\delta_{j}^{h}}-\left(1-\pi_{j}\right) \eta_{j}^{h}\left(\varepsilon_{j}^{\prime}\right)\right]\right)}{\left(1+r_{j}\left(\widetilde{k}_{j}^{\prime}, \varepsilon_{j}^{\prime}\right)\right)^{\gamma}}\right] 1
\end{aligned}
$$

Intuitively, optimal savings $\widetilde{s}_{j}$ follows from the household's Euler Equation, whereas (18) expresses a no-arbitrage condition for human and physical capital. Equations (17)-(18) thus implicitly characterize how cyclone risk affects equilibrium savings and investments which,

$\left.\left(\widehat{\beta_{1}^{A}}+\widehat{\beta_{2}^{A}}+\ldots+\widehat{\beta_{5}^{A}}\right) \varepsilon_{j, t}\right)$ based on Col. 2 in Table 4. Given that our analysis compares steady-state growth rates, the latter measure serves as upper bound on the implications of the lagged model. 
in turn, alter growth. Long-run or average growth then equals (see Online Appendix):

$$
\bar{g}_{j} \equiv E\left[\frac{c_{j}^{\prime}}{c_{j}}\right]=\left(\widetilde{s}_{j}\right)\left(1+E_{j}\left[r_{j}\left(\widetilde{k}_{j}^{\prime}, \varepsilon_{j}^{\prime}\right)\right]\right)
$$

Realized year-to-year growth $g_{j, t}$, in turn, is given by:

$$
g_{j, t}=\frac{c_{j, t}}{c_{j, t-1}}=\left(\widetilde{s}_{j}\right)\left[1+r_{j}\left(\widetilde{k}_{j, t}, \varepsilon_{j, t}\right)\right]
$$

Equations (15)- (20) illustrate how the model captures the cyclone-growth impact mechanisms described in Section 2. As these results are qualitatively standard, we relegate their formal illustration to the Online Appendix, and only summarize the key points here. First, if households are sufficiently risk averse, an increase in cyclone risk may increase the equilibrium savings rate (17), thus increasing long-run growth (19), ceteris paribus. Second, if human and physical capital have different vulnerability to storms $\left(\eta_{j}^{h}\left(\varepsilon_{j, t}\right) \neq \eta_{j}^{k}\left(\varepsilon_{j, t}\right)\right)$, an increase in cyclone risk may change the household's optimal portfolio allocation $\widetilde{k}_{j}$ (defined by (18)). In particular, if physical capital is more susceptible to storms, higher cyclone risk may induce households to invest relatively more in human capital. Third, higher storm risk increases average depreciation and lowers TFP, thus decreasing average returns and hence long-term growth 199, ceteris paribus. In sum, an increase in cyclone risk thus has a theoretically ambiguous impact on average growth, whereas a cyclone strike unambiguously reduces realized returns (15) and thus year-to-year growth (20), in line with the empirical evidence. Finally, the model also captures the empirical stylized facts that cyclone strike impacts persistently decrease output levels.

In sum, our parsimonious model thus arguably matches several of the empirical literature's key findings. Of course it also has some shortcomings that should be noted. Human capital accumulation does not induce a positive growth externality à la Lucas (1988), so that the benefits of increased human capital may be understated. More broadly, endogenous growth models differ in the underlying source of growth. The present framework features constant returns to scale in reproducible factors. This class of models is standard in modern stochastic growth models, including in many analyses of disasters and growth (e.g., Pindyck and Wang, 2013; Bretschger and Vinogradova, 2016), quantitative models of human capital risk over the business cycle (e.g., Krebs, 2003ab, 2015) and also leading advancements in stochastic climate-economy modeling (e.g., van den Bremer and van der Ploeg, 2018). At the same time, this structure has known shortcomings in matching certain moments such as on cross-country convergence (Mankiw, Romer, Weil, 1994). While alternative models may thus better explain advancements in international technology frontiers and the growth of 
mature economies, for capturing the marginal effects of cyclone risk changes on growth, we argue that our model provides a natural starting point firmly in line with related literature. We also note that the core contribution of this paper lies in its joint empirical-structural approach to climate change impact estimation, which can readily be extended to other types of models. Indeed, Section 6 integrates our damage functions into the seminal DICE model, a Ramsey growth framework (Nordhaus, e.g., 2010a).

\subsubsection{Quantification}

We quantify the model for each country using a combination of data, estimation, matching of moments, and external calibration. Table 6 summarizes the calibration strategy. Initial capital stock levels $\left(K_{0, j}\right)$ are taken directly from the data (Penn World Tables), with a model base year (indexed by 0 ) of 2014. Human capital stocks are backed out via $H_{0, j}=\frac{K_{0, j}}{\widetilde{k}_{0, j}}$ after solving for initial asset allocation ratios $\left(\widetilde{k}_{0, j}\right)$ as described below. We obtain estimates of the currently insured fraction of disaster damages from MunichRe's NatCatService, which range from $55 \%$ in high income countries to only $3.3 \%$ in low income countries ${ }^{24}{ }^{25}$ Cyclone risk pdfs $\left(f_{j}\left(\varepsilon \mid T_{\tau}\right)\right)$ and damage functions $\left(\eta_{j}^{k}(\varepsilon), \eta_{j}^{h}(\varepsilon), \eta_{j}^{A}(\varepsilon)\right)$ are as estimated in Sections 4 and 3 , respectively. Baseline (i.e., non-cyclone) depreciation rates $\left(\underline{\delta_{k}}, \underline{\delta_{h}}\right)$ are calibrated at standard rates from the literature, as are the capital share $(\alpha)$, utility discount factor $(\beta)$, and coefficient of relative risk aversion $(\mathrm{CRR}, \gamma)$. Finally, our calibration then matches observed base year GDP per capita growth $g_{0, j}$ (from Penn World Tables) at base year cyclone realizations $\varepsilon_{0, j}$ (from IBTrACS) in each country by solving jointly for initial productivity level $\bar{A}_{0, j}$, savings-out-of-wealth rates $\widetilde{s}_{0, j}$, and asset allocation ratios $\widetilde{k}_{0, j}$ via $(17),(18)$, and (20) 26

We first consider the ceteris paribus effect of changing cyclone risks in today's economy, with insurance rates and damage functions evaluated at current covariate levels. Welfare changes are measured as percent change in stationary equilibrium welfare under the current versus future climate. Figures 4 and 5 present the results for projected welfare and growth impacts, respectively (dark bars). The results reveal significant heterogeneity in

24 In upper middle income countries, the fraction is $11.7 \%$, and in lower middle income countries, $5.2 \%$. Income groupings are based on 2017 gross national income per capita as per World Bank classification.

25 Deryugina (2017) shows that general fiscal transfers constitute an important source of implicit disaster insurance in the U.S., suggesting that our base insurance measure may be an underestimate in similar countries. We consider higher insurance rates based on future income adjustments, as described below.

26 At this step we drop six countries from the sample that experienced negative growth in 2014, in some cases severely so due to warfare or other non-modeled crises (e.g., Yemen, Venezuela). Seeking to match their growth rates yields problematic calibration results, such as savings-out-of-wealth ratios in excess of unity. The other dropped countries are Oman, St. Lucia, The Bahamas, and the British Virgin Islands. 


\begin{tabular}{|lll|}
\hline \multicolumn{3}{|l|}{ Table 6: Model Calibration } \\
\hline \hline \multicolumn{2}{|l|}{ Country-Specific from Data, Estimation, Matched Moments } \\
\hline Item & Description & Source or Value \\
$K_{0, j}$ & Capital stock & PWT Data \\
$\pi_{j}$ & Insured fraction & MunichRe NatCatService \\
$H_{0, j}$ & Human capital & Back out via $H_{0, j}=\frac{K_{0, j}}{\widetilde{k}_{0, j}}$ given investment ratio $\widetilde{k}_{0, j}$ \\
$f_{j}\left(\varepsilon \mid T_{\tau}\right)$ & Cyclone risk pdf & Estimated from IBTrACS cyclone records, Emanuel et \\
& & al. $(2008)$ synthetic tracks, see Section 4 \\
$\eta_{j}^{k}(\varepsilon), \eta_{j}^{h}(\varepsilon)$ & Damage & Estimated from global macro panel, damage data; see \\
$\eta_{j}^{A}(\varepsilon)$ & functions & Section 3 \\
$\mathcal{A}_{0, j}$ & TFP & Match initial GDP growth $\left(\right.$ PWT) given $\widetilde{s}_{0, j}, \widetilde{k}_{0, j}$ \\
$\widetilde{s}_{0, j}$ & Savings/wealth & Model \\
$\widetilde{k}_{0, j}$ & Investment ratio & Model \\
\hline Globally Standard from Literature \\
\hline$\alpha$ & Capital share & 0.33 \\
$\frac{\delta_{k}}{\delta_{h}}$ & Baseline depr. & $10 \% / y r$ \\
$\frac{\gamma}{\beta}$ & Baseline depr. & $10 \% / y r$ \\
$\beta$ & Risk Aversion & 2 \\
\hline
\end{tabular}

the projected effects of climate-induced cyclone risk changes across countries, ranging from substantial negative impacts in vulnerable small island states (e.g., a -6\% welfare change in St. Vincent and the Grenadines) to small welfare gains in countries where cyclone risks are predicted to decline with global warming. The predicted growth impacts mirror this heterogeneity, but are generally smaller in magnitude. Another striking result is that the United States stands out among the 'top 10' of most negatively impacted countries, which are otherwise mostly poor and/or small island states. This result is in line with empirical evidence that the United States appears uniquely vulnerable to hurricanes given its levels of income and exposure (see, e.g., Bakkensen and Mendelsohn, 2016).

We next consider the combination of future cyclone and vulnerability changes by evaluating damage coefficients at projected future (2095-2105) levels of GDP and the population share living below five meters elevation, respectively ${ }^{27}$ and allowing insurance rates to increase along with projected economic development ${ }^{28}$ The results are also displayed in Figures 3 and 4 (light grey bars). We find that reductions in future cyclone vulnerability due to continued economic development may vastly mitigate the potential losses from future cyclone

27 GDP projections are based on regionally differentiated business-as-usual per capita GDP growth projections from the RICE model (Nordhaus, 2011), applied to each country's GDP per capita levels in 2015. Low elevation population projections to 2100 are from CIESIN (2013).

28 We assume that the relationship between incomes and insurance remains as currently observed in MunichRe data, and assign 2095 insurance rates based on countries' projected future incomes. 
risk increases. Indeed, there are a number of cases where the ceteris paribus welfare impacts of cyclone risk increases may be substantial and negative, but where the combined effect of future changes in cyclone risk and vulnerability is predicted to be positive (e.g., Comoros, Belize, Haiti, Mozambique, etc.). That is, in a 'horse race', the protective effects of economic and insurance market development are predicted to outweigh cyclone risk increases in several countries. Of course we must caution that there are further sources of future vulnerability change that are not included in our model, such as learning from increased cyclone exposure conditional on income (which would decrease future vulnerability, ceteris paribus, see, e.g., Schumacher and Strobl, 2011; Hsiang and Narita, 2012; and Fried, 2019), or sea level rise (which will increase future vulnerability to storms conditional on intensity, ceteris paribus).

We present additional model results for a number of alternative specifications in the Online Appendix, including for 5-year TFP impacts, three alternative climate models (MIROC, CNRM, and ECHAM), and for the MunichRe data-based capital depreciation function. As expected, the cumulative TFP impacts specification generally implies higher welfare losses associated with cyclone risk increases. For example, Haiti's predicted welfare impacts of ceteris paribus cyclone risk changes increase from $-0.56 \%$ in the benchmark to $-1.84 \%$ in this specification. At the same time, cumulative TFP impacts can also increase the welfare gains associated with cyclone risk declines. For example, Japan's welfare impacts of ceteris paribus cyclone risk changes increase from $+0.024 \%$ to $+0.12 \%$. For the other sensitivity runs, we find that the model predictions have mixed sensitivity to these changes. In some countries, there are qualitative differences across climate models. For example, in Bangladesh, while the benchmark model implies a cyclone risk decline, other climate models predict increases in cyclone risk with global warming, and associated negative welfare impacts. Conversely, in the Dominican Republic, the MIROC climate model predicts a cyclone risk decrease implying a welfare gain, whereas our benchmark scenario implies a cyclone risk increase and corresponding welfare loss. Similarly, the MunichRe-based damage function increases the projected welfare costs of cyclone risk changes in, e.g., the United States (from $-0.25 \%$ to $-0.31 \%$ ) , but also increases welfare gains in countries predicted to experience cyclone risk declines, such as Japan (from $+0.024 \%$ to $+0.033 \%$ ). In other cases, the results appear similar. We address the overall sensitivity of the results to these variations through an analogous sensitivity check in the DICE model extension. While individual country predictions may vary, we find that the aggregate costs of climate-induced cyclone risk changes appear broadly robust to these model variations, as shown in the next section. 


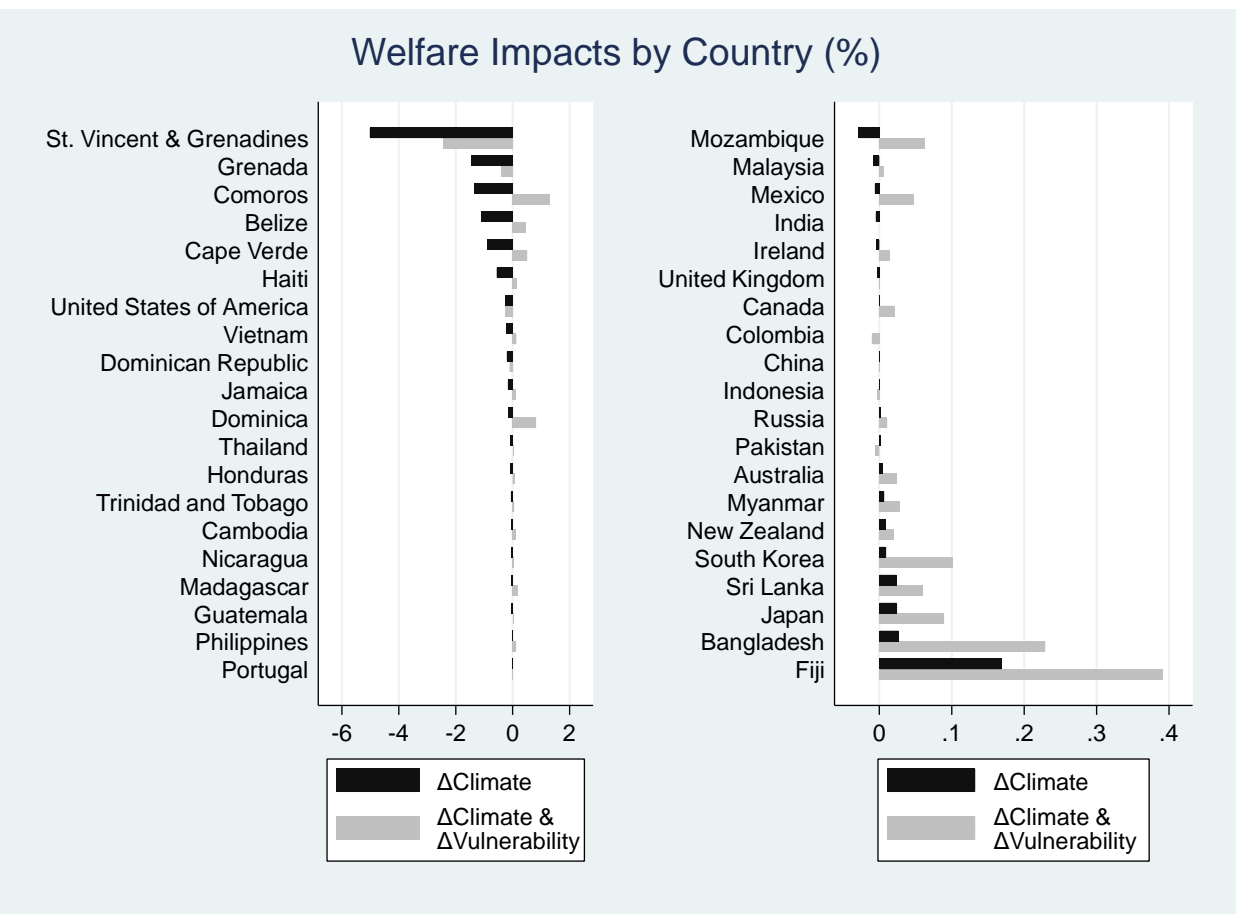

Figure 3

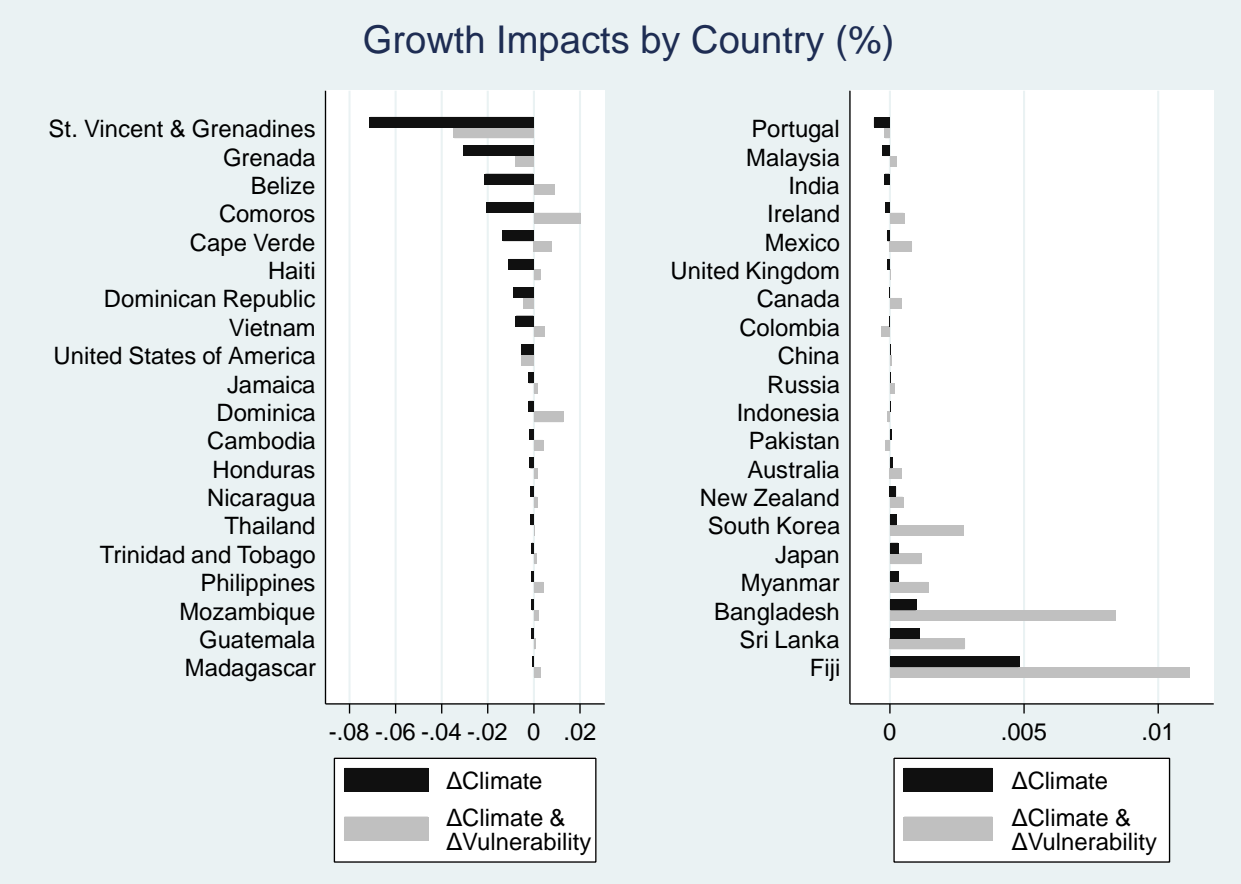

Figure 4 


\section{DICE Model Integration}

In order to gauge the aggregate implications of cyclone risk changes for global climate policy, this section concludes by presenting an integration of our damage functions into the seminal DICE climate-economy model (Nordhaus, e.g., 1992, 2011). DICE serves as a central benchmark across the literature, and is one of three frameworks used by the U.S. government to value the social cost of carbon (Greenstone, Kopits, and Wolverton, 2013).

The DICE model is deterministic and specifies climate change impacts as output-equivalent loss $D\left(T_{\tau}\right)$ as a function of the mean global atmospheric temperature change $T_{\tau}$ in decade $\tau$. The first step in mapping our estimates into DICE is thus to compute expected annual capital depreciation, fatalities, and TFP losses under different climates for each country. Specifically, we use our estimates for damage function (8) and cyclone $p d f s$ for each country to compute:

$$
\begin{aligned}
& E_{j}\left[\eta_{j, t}^{k}(\varepsilon) \mid T_{\tau}\right]=\int_{0}^{\infty} \delta_{j, t}^{h}(\varepsilon) \cdot f_{j}\left(\varepsilon \mid T_{\tau}\right) d \varepsilon \\
& E_{j}\left[\eta_{j, t}^{h}(\varepsilon) \mid T_{\tau}\right]=\int_{0}^{\infty} \delta_{j, t}^{h}(\varepsilon) \cdot f_{j}\left(\varepsilon \mid T_{\tau}\right) d \varepsilon
\end{aligned}
$$

For TFP impacts, we focus on the cumulative damage specification $\eta^{A}\left(\varepsilon_{j, t}, \ldots \varepsilon_{j, t-4}\right)=\widehat{\beta_{1}^{A}} \varepsilon_{j, t}+$ $\widehat{\beta_{2}^{A}} \varepsilon_{j, t-1}+\ldots+\widehat{\beta_{5}^{A}} \varepsilon_{j, t-4}$ as our aggregate effects ultimately appear to be quite modest. Assuming independence in year-to-year cyclone fluctuations, expected annual cyclone TFP impacts in country $j$ can then be estimated through an analogous specification to (21). As a second step, we then aggregate expected impacts across countries, using global GDP shares as weights for TFP impacts, global capital shares as weights for physical depreciation impacts, and populations as weights for fatality impacts. Table 8 presents the resulting estimates of global aggregate expected annual cyclone impacts under the current and future climate, respectively.

These results reveal the following insights. First, global heterogeneity in projected cyclone risk changes across countries nets out to an increase in aggregate expected damages. For example, annual expected global TFP losses due to cyclones are projected to increase by around $14 \%$ (from $0.0288 \%$ to $0.0329 \%$ ). With fixed damage functions, capital depreciation is moreover predicted to increase by around $75 \%$; for fatalities, the relevant figure is $5-11 \%$. Second, while the levels of estimated losses may appear small, their magnitude is broadly in line with historical data. While cyclones can be locally extremely destructive, their impacts are limited both geographically and physically, especially as a fraction of global capital stocks and populations. 
Table 8: Global Aggregate Annual Expected Cyclone Depreciation (\%/year)

\begin{tabular}{lc|c}
\hline \hline & Current Climate & Future Climate $\left(T_{2090}\right)$ \\
\hline \hline TFP (DICE) & $0.0288 \%$ & $.0329 \%$ \\
\hline \hline Physical Capital & & \\
\hline Damage Fn. Coefficients: & & \\
Country-Fixed; U.S. sep. & $.0062 \%$ & $.0109 \%$ \\
Current GDP, Pop $<5 \mathrm{~m}$; U.S. sep. & $.0062 \%$ & $.0112 \%$ \\
Future GDP, Pop $<5 \mathrm{~m}$; U.S. sep. & $.0042 \%$ & $.0087 \%$ \\
Future GDP, Pop $<5 \mathrm{~m}$ & $.0018 \%$ & $.0016 \%$ \\
Historical Data: & & \\
\hline Avg. (1970-2014) & $.0091 \%$ & \\
Year 2014 & $.0050 \%$ & \\
\hline \hline Fatalities & & \\
\hline Damage Fn. Coefficients: & & \\
Country-Fixed & $.000040 \%$ & $.000042 \%$ \\
Current GDP, Pop $<5 \mathrm{~m}$ & $.000035 \%$ & $.000039 \%$ \\
Future GDP, Pop $<5 \mathrm{~m}$ & $.000004 \%$ & $.000005 \%$ \\
Historical Data: & & \\
\hline Avg. (1970-2015) & $.000422 \%$ & \\
Year 2014 & $.000008 \%$ & \\
\hline
\end{tabular}

For example, even the $\$ 108$ billion in damages caused by Hurricane Katrina - the costliest storm in U.S. history - accounted for only $0.24 \%$ of the U.S. capital stock at the time, $(\$ 44.4$ trillion, $\$ 2011$ ), or $0.042 \%$ of the global capital stock. A third result to emerge from Table 8 is the critical importance of U.S. cyclone damages for the global aggregate. For example, if we project future damages assuming that the United States will maintain its separate damage function (based on Column 2 of Table 5), global capital losses are estimated to be $0.0087 \%$ per year. If, instead, we assume that the United States will follow other countries' pattern of decreasing vulnerability with further economic development (based on Column 4 of Table 5), projected global capital losses are only $0.0016 \%$. That is, limited adaptation to cyclones in the U.S. could increase global damages by more than a factor of five. These results thus highlight the importance of ongoing research illuminating distinct U.S. cyclone damage patterns (e.g., Nordhaus, 2010b; Conte and Kelly, 2016; Bakkensen and Mendelsohn, 2016; Fried, 2019).

The next step in the DICE model integration is to convert our estimates into climate damage functions, which ought to reflect only the additional impacts due to warming $T_{\tau}$ in decade $\tau$. The benchmark DICE model aggregates climate impacts into an output-equivalent loss $D\left(T_{\tau}\right)$. That is, available (net of damages) output in DICE differs from (3) via:

$$
Y_{\tau}^{D I C E}=\left(1-D\left(T_{\tau}\right)\right) A_{j, t}^{D I C E} K_{j, t}^{\alpha_{D}}\left(L_{j, t}^{P o p}\right)^{1-\alpha_{D}}
$$


We add three cyclone-specific damage functions into DICE. First, we integrate cycloneinduced capital depreciation explicitly into the model's law of motion for capital by making the depreciation rate a function of the climate $\delta\left(T_{\tau}\right)$ (and where $I_{\tau}$ denotes investment):

$$
K_{\tau+1}=K_{\tau}\left(1-\delta\left(T_{\tau}\right)\right)+I_{\tau}
$$

Second, for fatality impacts, we introduce an effective labor parameter $Z_{H}\left(\mathbf{T}_{\boldsymbol{\tau}}\right)$ designed to capture the cumulative loss in the effective work force due to climate change up until time $\tau$ with $\mathbf{T}_{\boldsymbol{\tau}} \equiv\left\{T_{\tau}, T_{\tau-1}, \ldots T_{0}\right\}{ }^{29}$ Third, for TFP impacts, we also specify an effective (i.e., net of cyclone damages) decadal productivity term $Z_{A}\left(T_{\tau}\right)$. The aggregate (net) production function in our extended DICE model is thus given by:

$$
Y_{\tau}^{D I C E+C y c l o n e s}=Z_{A}\left(T_{\tau}\right) \cdot\left(1-D\left(T_{\tau}\right)\right) A_{j, t}^{D I C E} K_{j, t}^{\alpha_{D}}\left[L_{j, t}^{P o p} \cdot Z_{H}\left(\mathbf{T}_{\boldsymbol{\tau}}\right)\right]^{1-\alpha_{D}}
$$

Given that natural scientists generally project the global cyclone intensity-temperature relationship to be linear (Holland and Bruyere, 2014), and adopting NOAA's assessment that anthropogenic warming between pre-industrial and current times has not yet altered tropical cyclone patterns (GFDL, 2018), we extrapolate linearly to convert the results of Table 8 into the following damage function parameterizations (see Online Appendix for details). First, letting $\underline{\delta}$ denote the benchmark annual depreciation rate assumed in DICE, and adding in annual expected cyclone damages, the decadal depreciation rate becomes:

$$
\delta\left(T_{\tau}\right)=1-\left[\left(1-\underline{\delta}-\widehat{\alpha_{k}} T_{\tau}\right)^{10}\right]
$$

The effective work force term $Z_{H}\left(\mathbf{T}_{\boldsymbol{\tau}}\right)$ is similarly given by:

$$
Z_{H}\left(\mathbf{T}_{\boldsymbol{\tau}}\right)=\prod_{j=0}^{\tau}\left(1-\widehat{\alpha_{h}} T_{\tau-j}\right)^{10}
$$

Intuitively, (24) equals one minus cumulative cyclone deaths through decade $\tau$. Finally, the effective TFP term is given by:

$$
Z_{A}\left(T_{\tau}\right)=1-\left[\left(1-\widehat{\alpha_{A}} T_{\tau}\right)^{10}\right]
$$

Each damage function specification in Table 8 implies different coefficient values for $\widehat{\alpha_{k}}$ and $\widehat{\alpha_{h}}$. Given that our social cost of carbon (SCC) impact estimates are generally modest, we

$29 \quad$ We choose this specification in lieu of explicit population losses as the DICE model's welfare weighting of future generations depend on their population size. It is standard for IAMs to value mortality without changing the assumed population in the model. 
focus on the largest $\widehat{\alpha}$ values which assume no future decreases in cyclone vulnerability. For sensitivity, we also present estimates for damage functions based on the MunichRe loss data (specifically for the fixed effects and U.S. depreciation specifications in Columns 1 and 2 of Table 6) and two alternative climate models, MIROC and CNRM (see Online Appendix for extended Table 8 including these models). Table 9 presents the results of incorporating damage functions (23)-25 into the 2010 DICE model, specifically the percentage increase in the (optimal) social cost of carbon in $2015\left(\triangle S C C_{2015}\right)$, and on average over the 21st century $\left(\overline{\triangle S C C_{2015-2115}}\right)$.

Table 9: Cyclone Impacts on the Social Cost of Carbon

\begin{tabular}{|llllll|}
\hline Impacts Case & $\widehat{\alpha_{A}}$ & $\widehat{\alpha_{h}}$ & $\widehat{\alpha_{k}}$ & $\Delta S C C_{2015}$ & $\overline{\Delta S C C_{2015-2115}}$ \\
\hline \hline Benchmark & .0000173 & $1.60 e^{-08}$ & .0000212 & $+0.9 \%$ & $+0.7 \%$ \\
\hline MIROC Climate Model & .0000281 & $4.50 e^{-08}$ & .0000067 & $+1.2 \%$ & $+1.0 \%$ \\
\hline CNRM Climate Model & .0000101 & $3.38 e^{-08}$ & .0000049 & $+0.5 \%$ & $+0.4 \%$ \\
\hline MunichRe Damages & .0000173 & $1.60 e^{-08}$ & .0000373 & $+1.0 \%$ & $+0.9 \%$ \\
\hline
\end{tabular}

In the aggregate, we find only modest increases in the optimal global social cost of carbon after integrating our estimated damage functions into DICE. Though perhaps surprising from the perspective of the United States, where cyclone damages are among the world's largest and projected to increases significantly with global warming, this result is less surprising in light of the substantial heterogeneity in expected cyclone-warming impacts around the world (see Figure 2). In addition, regional cyclone impacts are modest relative to the global economy. Nonetheless, there are reasons to suspect that our estimates may understate the true SCC impact of tropical cyclone changes. First, as DICE is deterministic, the welfare costs of uninsurable risk changes and behavioral responses thereto are not accounted for. Second, our estimates exclude some cyclone-vulnerable countries due to data limitations, and may of course be generally attenuated due to measurement error. Third, our estimates also do not account for potential future cyclone vulnerability increases due to sea level rise. At the same time, they also do not account for some mechanisms that may decrease future vulnerability, such as learning-based adaptation conditional on income, or technological innovations. Ceteris paribus, these omissions would be expected to bias our SCC estimates upwards. As a growing empirical literature continues to explore these issues, it would be a rich area for future work to build on the frameworks presented in this paper to integrate new empirical evidence into structural environment-economy models. 


\section{Conclusion}

This paper proposes a novel empirical-structural approach to analyze the macroeconomic consequences of climate change with a focus on tropical cyclones. We first empirically and conceptually review competing approaches to quantifying cyclone impacts on growth. We highlight that differences in reduced-form findings, driven in part by empirical choices, are maintained using a comprehensive dataset yet can also be reconciled through a theoretical lens. Importantly, theory also tells us that even perfectly identified reduced-form regressions of growth on cyclone shocks or risk may not be individually sufficient to characterize the welfare effects of future changes in cyclone risks given broader general equilibrium changes.

Second, we present our approach to estimating and modeling cyclone impacts designed to combine empirical evidence with the structure of a model to deliver welfare cost estimates and policy implications. We propose that empirical research focus on quantifying cyclone impacts on the structural determinants of growth, and not just growth itself, as the latter is typically endogenous in macroeconomic climate-economy models. We then present a stochastic endogenous growth cyclone-climate-economy model that we quantify separately for 40 cyclone-vulnerable nations. Important for policy, we find significant heterogeneity of projected climate change impacts, ranging from substantial negative effects in vulnerable small island states, to small welfare gains in countries where cyclone risks are predicted to decline with global warming. The United States stands out among the most negatively impacted countries.

Third, in order to assess the global climate policy implications of changing cyclone risks, we integrate our cyclone impact estimates into the seminal DICE model and assess their impact on the social cost of carbon. More broadly, our approach highlights opportunities to reduce the "micro-macro" gap between growing empirical evidence on macroeconomic impacts and the quantification climate-economy models. We show that only minor extensions of existing empirical approaches yield structurally interpretable impact estimates. We also demonstrate how modifying climate-economy model structure to make weather explicit permits (i) direct incorporation of plausibly causally identified impact estimates, (ii) accounting for macroeconomic adaptation through endogenous adjustments in savings and investments, and (iii) computing welfare costs of changes in climatic risks. As frontier advancements in stochastic climate-economy models are now able to account for multiple sources of uncertainty at high frequency (Cai and Lontzek, 2019), extending a truly integrated assessment models to explicit consideration of weather impacts may thus be an interesting area for future work and facilitate linkages to the empirical literature. Similarly, while our quantitative results are subject to numerous limitations ranging from our abstractions of advancements 
in wind-field modeling (Strobl, 2011; Hsiang and Narita, 2012) to distinguishing productive and adaptation capital (e.g., Fried, 2019), our proposed method seeks to complement these empirical and modeling advancements so as to facilitate the integration of both frontiers and to improve our understanding of the social costs of climate change.

\section{References}

[1] Acemoglu, D., Johnson, S., \& Robinson, J. A. (2001). "Reversal of fortune: Geography and institutions in the making of the modern world income distribution (No. w8460)." National bureau of economic research.

[2] Aiyagari, S. Rao (1994) "Uninsured idiosyncratic risk and aggregate saving." The Quarterly Journal of Economics: 659-684.

[3] Akao, Ken-Ichi, and Hiroaki Sakamoto "A Theory of Disasters and Long-Run Growth" RIETI Discussion Paper 13-E-061 (2013).

[4] Albala-Bertrand, J. M. (1993). "Natural disaster situations and growth: A macroeconomic model for sudden disaster impacts." World Development, 21(9), 1417-1434.

[5] Atkinson, Gary D., and Charles R. Holliday. "Tropical cyclone minimum sea level pressure/maximum sustained wind relationship for the western North Pacific." Monthly Weather Review 105, no. 4 (1977): 421-427.

[6] Auffhammer, Maximilian. "Quantifying economic damages from climate change." Journal of Economic Perspectives 32, no. 4 (2018): 33-52.

[7] Bakkensen, Laura, and Lint Barrage. "Do disasters affect growth? A macro model-based perspective on the empirical debate." No. 2016-9. Working Paper, Brown University, Department of Economics. (2016).

[8] Bakkensen, Laura A., and Robert O. Mendelsohn. "Risk and adaptation: evidence from global hurricane damages and fatalities." Journal of the Association of Environmental and Resource Economists 3, no. 3 (2016): 555-587.

[9] Bansal, Ravi, and Marcelo Ochoa. "Temperature, Aggregate Risk, and Expected Returns" (2011) NBER Working Paper \#17575.

[10] Barro, Robert J. "Rare disasters and asset markets in the twentieth century." The Quarterly Journal of Economics 121, no. 3 (2006): 823-866.

[11] Barro, Robert J., and Jong Wha Lee. "A new data set of educational attainment in the world, 1950-2010." Journal of development economics 104 (2012): 184-198.

[12] Bewley, T. F. (1997) "The Permanent Income Hypothesis: A Theoretical Formulation." J. Econ. Theory 16: 252-92. 
[13] Bovenberg, A. Lans, and Sjak Smulders. "Environmental quality and pollutionaugmenting technological change in a two-sector endogenous growth model." Journal of Public Economics 57, no. 3 (1995): 369-391.

[14] van den Bremer Ton, and Rick van der Ploeg. "The Risk-Adjusted Carbon Price." (2018). Working Paper.

[15] Bretschger, Lucas, and Simone Valente. "Climate change and uneven development." The Scandinavian Journal of Economics 113, no. 4 (2011): 825-845.

[16] Bretschger, L. and Vinogradova, A., 2018. Escaping Damocles' sword: Endogenous climate shocks in a growing economy. CER-ETH-Center of Economic Research at ETH Zurich, Working Paper, 18, p.291.

[17] Burke, Marshall, Solomon M. Hsiang, and Edward Miguel. "Global non-linear effect of temperature on economic production." Nature 527.7577 (2015): 235.

[18] Cai, Yongyang, and Thomas S. Lontzek. "The social cost of carbon with economic and climate risks." Journal of Political Economy 127, no. 6 (2019).

[19] Cavallo, Eduardo, Sebastian Galiani, Ilan Noy, and Juan Pantano. "Catastrophic natural disasters and economic growth." Review of Economics and Statistics 95, no. 5 (2013): 1549-1561.

[20] Colacito, Ric, Bridget Hoffmann, Toan Phan. "Temperatures and growth: A panel analysis of the United States." Journal of Money, Credit, and Banking 51, no. 2-3 (2018): 2019.

[21] Conte, Marc N., and David L. Kelly. "An Imperfect Storm: Fat-Tailed Hurricane Damages, Insurance, and Climate Policy." Working Paper. No. 2016-01 (2016).

[22] Dell, Melissa, Benjamin F. Jones, and Benjamin A. Olken. "Temperature shocks and economic growth: Evidence from the last half century." American Economic Journal: Macroeconomics 4, no. 3 (2012): 66-95.

[23] Deryugina, T. "The fiscal cost of hurricanes: Disaster aid versus social insurance." American Economic Journal: Economic Policy, 9, no. 3 (2017): 168-98.

[24] Deryugina, Tatyana, and Solomon Hsiang. "The marginal product of climate." (2017). No. w24072. National Bureau of Economic Research.

[25] Devereux, Michael B., and Gregor W. Smith. "International risk sharing and economic growth." International Economic Review (1994): 535-550.

[26] Dietz, Simon, and Nicholas Stern. "Endogenous growth, convexity of damage and climate risk: how Nordhaus' framework supports deep cuts in carbon emissions." The Economic Journal 125, no. 583 (2015): 574-620. 
[27] Elliott, Robert, Eric Strobl, Puyang Sun. "The local impact of typhoons on economic activity in China: A view from outer space." Journal of Urban Economics 88 (2015): $50-66$.

[28] Emanuel, Kerry A. "The Hurricane climate connection." Bulletin of the American Meteorological Society, 89(5) (2008): ES10-ES20.

[29] Emanuel, Kerry A. "Downscaling CMIP5 climate models shows increased tropical cyclone activity over the 21st century." Proceedings of the National Academy of Sciences 110, no. 30 (2013): 12219-12224.

[30] Emanuel, Kerry, Ragoth Sundararajan, and John Williams. "Hurricanes and global warming: Results from downscaling IPCC AR4 simulations." Bulletin of the American Meteorological Society 89.3 (2008): 347-368.

[31] Fankhauser, Samuel, and Richard SJ Tol. "On climate change and economic growth." Resource and Energy Economics 27, no. 1 (2005): 1-17.

[32] Feenstra, Robert C., Robert Inklaar, and Marcel P. Timmer. "The next generation of the Penn World Table." American Economic Review 105, no. 10 (2015): 3150-82.

[33] Fomby, Thomas, Ikeda, Y., and Loayza, N. V. The growth aftermath of natural disasters. Journal of Applied Econometrics, 28 no. 3 (2013): 412-434.

[34] Fried, Stephie. "Seawalls and Stilts: A Quantitative Macro Study of Climate Adaption" (2019) Working Paper.

[35] GFDL (Geophysical Fluid Dynamics Laboratory). "Global Warming and Hurricanes." Available online at: https://www.gfdl.noaa.gov/global-warming-and-hurricanes/. Accessed July 2, 2018.

[36] Gollin, Douglas. "Getting income shares right." Journal of Political Economy 110, no. 2 (2002): 458-474.

[37] Greenstone, Michael. "A New Path Forward for an Empirical Social Cost of Carbon." (2016). Presentation to the National Academies of Sciences, https://sites.nationalacademies.org/cs/groups/dbassesite/documents/webpage/dbasse_172599.pdf.

[38] Greenstone, Michael, Elizabeth Kopits, and Ann Wolverton. "Developing a social cost of carbon for US regulatory analysis: A methodology and interpretation." Review of Environmental Economics and Policy 7, no. 1 (2013): 23-46.

[39] Guha-Sapir, Debarati, Regina Below, and Philippe Hoyois. "EM-DAT: The CRED." OFDA International Disaster Database-www. emdat. be-Université Catholique de Louvain-Brussels-Belgium (2016).

[40] Guha-Sapir, Debarati, and Regina Below. "The Quality and Accuracy of Disaster Data: A Comparative Analyses of Three Global Datasets" World Bank Disaster Management Facility, Pro Vention Consortium (2002). 
[41] Hall, Robert E., and Charles I. Jones. "Why do some countries produce so much more output per worker than others?." The Quarterly Journal of Economics 114, no. 1 (1999): $83-116$.

[42] Hall, R. E., \& Jones, C. I. (1996). "The productivity of nations (No. w5812)." National Bureau of Economic Research.

[43] Hallegatte, Stéphane. "The use of synthetic hurricane tracks in risk analysis and climate change damage assessment." Journal of applied meteorology and climatology 46, no. 11 (2007): 1956-1966.

[44] Hallegatte, Stéphane. "Roadmap to assess the economic cost of climate change with an application to hurricanes in the United States." In Hurricanes and Climate Change (pp. 361-386). (2009). Springer, Boston, MA.

[45] Hallegatte, Stéphane, Jean-Charles Hourcade, and Patrice Dumas. "Why economic dynamics matter in assessing climate change damages: illustration on extreme events." Ecological economics 62.2 (2007): 330-340.

[46] Holland, Greg, and Cindy L. Bruyère. "Recent intense hurricane response to global climate change." Climate Dynamics 42, no. 3-4 (2014): 617-627.

[47] Holland, Greg, and Kerry Emanuel (2011) "Limits on Hurricane Intensity" Kerry Emanuel Website (accessed July 2018), URL: [https://emanuel.mit.edu/limitshurricane-intensity]

[48] Hsiang, Solomon M., and Amir S. Jina. "The causal effect of environmental catastrophe on long-run economic growth: Evidence from 6,700 cyclones." NBER WP 20352 (2014).

[49] Hsiang, Solomon M., and Amir S. Jina. "Geography, depreciation, and growth." American Economic Review 105, no. 5 (2015): 252-56.

[50] Hsiang, Solomon M., and Daiju Narita. "Adaptation to cyclone risk: Evidence from the global cross-section." Climate Change Economics 3, no. 02 (2012): 1250011.

[51] Ikefuji, Masako, and Ryo Horii. "Natural disasters in a two-sector model of endogenous growth." Journal of Public Economics 96, no. 9-10 (2012): 784-796.

[52] Inklaar, Robert, and Marcel P. Timmer. "Capital, Labor and TFP in PWT8. 0." University of Groningen, (2013).

[53] Johnson, Mark E., and Charles C. Watson Jr. "Fitting statistical distributions to data in hurricane modeling." American Journal of Mathematical and Management Sciences 27, no. 3-4 (2007): 479-498.

[54] Kahn, Matthew E. "The death toll from natural disasters: the role of income, geography, and institutions." Review of economics and statistics 87, no. 2 (2005): 271-284. 
[55] Knapp, K. R., M. C. Kruk, D. H. Levinson, H. J. Diamond, and C. J. Neumann. "The International Best Track Archive for Climate Stewardship (IBTrACS): Unifying tropical cyclone best track data." Bulletin of the American Meteorological Society, 91(2010): 363-376.

[56] Kousky, Carolyn. "Informing climate adaptation: A review of the economic costs of natural disasters." Energy Economics 46 (2014): 576-592.

[57] Krebs, Tom. "Human capital risk and economic growth." The Quarterly Journal of Economics 118, no. 2 (2003a): 709-744.

[58] Krebs, Tom. "Growth and welfare effects of business cycles in economies with idiosyncratic human capital risk." Review of Economic Dynamics 6, no. 4 (2003b): 846-868.

[59] Krebs, Tom. "Recursive equilibrium in endogenous growth models with incomplete markets." Economic Theory 29, no. 3 (2006): 505-523.

[60] Krebs, Tom., M. Kuhn, and M. Wright "Human Capital Risk, Contract Enforcement, and the Macroeconomy" American Economic Review, 105(11) (2015): 3223-3272.

[61] Lemoine, Derek. "Estimating the Consequences of Climate Change from Variation in Weather." (2019) Working paper.

[62] Lemoine, Derek. "The Climate Risk Premium: How Uncertainty Affects the Social Cost of Carbon." (2019) Working paper.

[63] Loayza, N., E. Olaberra, J. Rigolini, and L. Christiansen. (2009). "Natural Disasters and Growth Going Beyond the Averages." World Bank Policy Research Working Paper 4980. Washington, DC, United States: The World Bank.

[64] Lucas, R. E. (1987). Models of business cycles (Vol. 26). Oxford: Basil Blackwell.

[65] Lucas Jr, Robert E. "On the mechanics of economic development." Journal of monetary economics 22.1 (1988): 3-42.

[66] Manabe, Syukaro, R. J. Stouffer, M. J. Spelman, and Ke Bryan. "Transient responses of a coupled ocean-atmosphere model to gradual changes of atmospheric CO2. Part I. Annual mean response." Journal of Climate 4, no. 8 (1991): 785-818.

[67] Mankiw, N. Gregory, David Romer, and David N. Weil. "A contribution to the empirics of economic growth." The Quarterly Journal of Economics 107.2 (1992): 407-437.

[68] McDermott, T. K., Barry, F., \& Tol, R. S. (2014). "Disasters and development: natural disasters, credit constraints, and economic growth." Oxford Economic Papers, 66(3), 750-773.

[69] Mendelsohn, Robert, Kerry Emanuel, Shun Chonabayashi, and Laura Bakkensen. "The impact of climate change on global tropical cyclone damage." Nature climate change 2, no. 3 (2012): 205. 
[70] Mendelsohn, Robert, William D. Nordhaus, and Daigee Shaw. "The impact of global warming on agriculture: a Ricardian analysis." The American economic review (1994): 753-771.

[71] Moore, Frances C., and Delavane B. Diaz. "Temperature impacts on economic growth warrant stringent mitigation policy." Nature Climate Change 5, no. 2 (2015): 127.

[72] Müller-Fürstenberger, Georg, and Ingmar Schumacher. "Insurance and climate-driven extreme events." Journal of Economic Dynamics and Control 54 (2015): 59-73.

[73] Narita, Daiju, Richard SJ Tol, and David Anthoff. "Damage costs of climate change through intensification of tropical cyclone activities: an application of FUND." Climate Research 39.2 (2009): 87-97.

[74] Neumayer, Eric, Thomas Plümper, and Fabian Barthel. "The political economy of natural disaster damage." Global Environmental Change 24 (2014): 8-19.

[75] Nordhaus, William D. "An optimal transition path for slowing climate change." Science 20 (1992): 1315-1319.

[76] Nordhaus, William D. "Economic aspects of global warming in a post-Copenhagen environment" Proceedings of the National Academy of Sciences, 107(26) (2010a): 1172111726.

[77] Nordhaus, William D. "The economics of hurricanes and implications of global warming." Climate Change Economics 1, no. 01 (2010b): 1-20.

[78] Nordhaus, William D. "Estimates of the social cost of carbon: background and results from the RICE-2011 model." No. w17540. National Bureau of Economic Research, (2011).

[79] Noy, Ilan. "The macroeconomic consequences of disasters." Journal of Development economics 88, no. 2 (2009): 221-231.

[80] Obama, Barack. "The irreversible momentum of clean energy." Science 355, no. 6321 (2017): 126-129.

[81] Pindyck, Robert S., and Neng Wang. "The economic and policy consequences of catastrophes." American Economic Journal: Economic Policy 5, no. 4 (2013): 306-39.

[82] Raddatz, Claudio. Are external shocks responsible for the instability of output in lowincome countries?. Journal of Development Economics, 84, no. 1 (2007): 155-187.

[83] Raddatz, Claudio. The wrath of God: macroeconomic costs of natural disasters. The World Bank, (2009).

[84] Ranson, Matthew, Carolyn Kousky, Matthias Ruth, Lesley Jantarasami, Allison Crimmins, and Lisa Tarquinio. "Tropical and extratropical cyclone damages under climate change." Climatic change 127, no. 2 (2014): 227-241. 
[85] Rubel, F., and M. Kottek, "Observed and projected climate shifts 1901-2100 depicted by world maps of the Köppen-Geiger climate classification." Meteorol. Z., 19 (2010): 135-141.

[86] Schumacher, Ingmar, and Eric Strobl. "Economic development and losses due to natural disasters: The role of hazard exposure." Ecological Economics 72 (2011): 97-105.

[87] Skidmore, Mark, and Hideki Toya. "Do natural disasters promote long-run growth?." Economic inquiry 40, no. 4 (2002): 664-687.

[88] Strobl, Eric. "The economic growth impact of hurricanes: evidence from US coastal counties." Review of Economics and Statistics 93, no. 2 (2011): 575-589. 